Portland State University

PDXScholar

2-7-1989

\title{
A Model of Suicidal Behavior In Latency Age Children Based on Developmental Object Relations Theory
}

Stephen Henry Michaelis

Portland State University

Follow this and additional works at: https://pdxscholar.library.pdx.edu/open_access_etds

Part of the Child Psychology Commons, and the Educational Psychology Commons Let us know how access to this document benefits you.

\section{Recommended Citation}

Michaelis, Stephen Henry, "A Model of Suicidal Behavior In Latency Age Children Based on Developmental Object Relations Theory" (1989). Dissertations and Theses. Paper 2939.

https://doi.org/10.15760/etd.2934

This Thesis is brought to you for free and open access. It has been accepted for inclusion in Dissertations and Theses by an authorized administrator of PDXScholar. Please contact us if we can make this document more accessible: pdxscholar@pdx.edu. 
AN ABSTRACT OF THE THESIS OF Stephen Henry Michael is for the Master of Science in Education presented February 7, 1989.

Title: A Model of Suicidal Behavior In Latency Age Children Based on Developmental object Relations Theory.

APPROVED BY THE MEMBERS OF THE THESIS COMMITTEE:

Dáve Capuzzi Chấp

Arthur F. Terry

O

Robert $E_{n}$ Jones

$\frac{1}{\text { David L. Cressler }}$

This thesis attempts to explicate the manifestation of suicidal behavior in latency age children based on developmental object relations theory. It asserts that the susceptibility to suicidal behavior becomes part of the child's developing ego organization during the first three years of life as the result of deviant or distorted 
emotional development. These disturbances interfere with the normal internalizing processes of the separationindividuation phases, including the development of psychological mechanisms.

To accomplish the purpose of the study, the thesis generally classifies object relations theory within the parameters of developmental psychopathology and specifically classifies it as a component of contemporary psychodynamic theory. Then follows an exposition of the separationindividuation process and attendant development of psychological mechanisms in normal and disturbed development. This section concludes by identifying the normally developing child around thirty-six months of age as possessing the capacity to unite disparate self and object images into a single, whole person for appropriate selfcomfort, self-image formation, and self-esteem regulation through having received primarily gratifying interactions with caregivers. The child with disturbed development lacks this capacity because of the internalization of primarily negative object-images through primarily negative interactions with caregivers. The child lacks trust in itself and in others, tends to perceive itself and others as all-good or all-bad, and experiences hostility and depression.

A definition of latency and a description of this developmental stage follows. Cognitive development marked 
by secondary thought processes and reliance upon dynamic psychological mechanisms--ego defenses--to sustain a behavioral and emotional equilibrium, rather than a diminution of drives, permit latency to become established. As part of the structure of latency, fantasy serves a defensive and adaptive function by providing an outlet for drive expression and for mastery of situations intrapsychically. Children with disturbances in ego organization have a less established structure of latency than do normal children, that is, they rely to a greater extent on psychological mechanisms characteristic of the separation-individuation phases.

A review of empirical and clinical research of suicidal children encompasses family environment; loss, depression, and hopelessness; cognitive functioning; and defense mechanisms. Suicidal children live in stressful, chaotic families with confused role relationships. Findings regarding the relationships among loss, depression, and hopelessness appear mixed although integrally related. Suicidal children conceive of impersonal death as final while construing personal death as reversible as a defensive maneuver. Suicidal fantasies constitute the precursors to suicidal planning and actions. Suicidal children show impaired ability to devise active coping strategies. They seem to rely excessively on ego defenses considered 
developmentally appropriate in early stages of development, such as introjection.

A synthesis of theoretical formulations and research findings sets forth the developmental sequence culminating in suicidal behavior. The model depicts a child's developing ego organization predisposed to depression, hostility, and low self-esteem caused by the internalization of a predominance of negative self- and object-images. It portrays susceptibility to suicidal behavior through the incapacity to exercise self-protection under stressful situations because of a reliance upon maladaptive ego defenses. Fantasies to relieve psychic pain as part of latency defenses transform into fantasies of suicide; these presage and allow for planning and, given the failure of ego defenses, suicidal behavior results. 
A MODEL OF SUICIDAL BEHAVIOR IN

LATENCY AGE CHILDREN BASED

ON DEVELOPMENTAL OBJECT RELATIONS THEORY

by

STEPHEN HENRY MICHAELIS

A thesis submitted in partial fulfillment of the requirements for the degree of

\author{
MASTER OF SCIENCE \\ in \\ EDUCATION
}

Portland State University

1989 
TO THE OFFICE OF GRADUATE STUDIES:

The members of the Committee approve the thesis of Stephen Henry Michael is presented February 7, 1989.

Dave Capuzzi/ Chatr

Arthur F. Terry

Robert E. JGhes

David L. Cressler

APPROVED:

Robert B. Everhart, Dean, Department of Education

Bernard Ross, Vice Provost for Graduate Studies 


\section{ACKNOWLEDGEMENTS}

Each member of my committee participated in an indispensable and personal way. I am grateful to Dave Capuzzi, Ph.D., Art Terry, Ph.D., and Robert Jones, Ph.D.

With loving gratitude I thank JoAnn Michaelis, M.F.A., M.A., for her foresight and patience throughout the course of this project.

To Dick Mase, M.A., who with selfless devotion has intervened with suicidal children and their families, I dedicate this thesis. 
TABLE OF CONTENTS

PAGE

ACKNOWLEDGEMENTS .............................. i i i

LIST DF FIGURES $\ldots \ldots \ldots \ldots \ldots \ldots \ldots \ldots \ldots \ldots \ldots \ldots \ldots \ldots \ldots$

CHAPTER

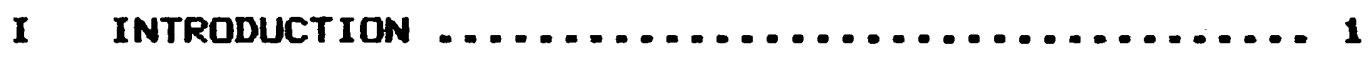

I I DEVELDPMENTAL DBJECT RELATIONS THEORY ........ 6

Developmental Psychopathology ............

Developmental object Relations Theory .....

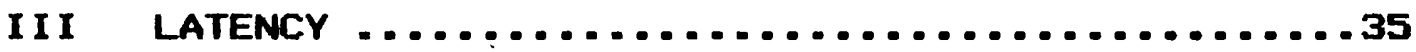

IV REVIEW OF THE LITERATURE ................. 48

Family Environment of Suicidal Children .. 48

Loss, Depression, Hopel essness .......... 56

Cognitive functioning ..............62

Psychological Mechanisms ............. 74 
$\checkmark$ CONCEPTUALIZATION OF SUICIDAL BEHAVIOR ...... 92

REFERENCES .................................. 103 


\section{LIST OF FIGURES}

F IGURE

PAGe

1. Nine Explanations of Stability and Change ........

2. Model of Suicidal Behavior ....................... 95 


\section{CHAPTER I}

\section{INTRODUCT ION}

Compared with the 50,000 to 500,000 suicide attempts and approximately 5,000 deaths per year in the 15 to 24 age range (Allen, 1987), or 12 per 100,000 (Pfeffer, 1986), the 200 suicides for 5 to 14 year-olds in 1982, or 0.6 per 100,000 (Pfeffer, 1986) appear low and have remained constant over the past 40 years (Shaffer \& Fisher, 1981a). For children aged 6 to 12 referred to psychiatric clinics, however, suicidal behavior--"any self-destructive behavior that has an intent to seriously damage oneself or cause death" (Pfeffer, 1986, P. 14)--has occurred in one-tenth to one-third of them (Hawton, 1982). Although suicide seldom occurs in children under 11 (Kienhorst, Wolters, Diekstra, \& Ottie, 1987), authorities agree "that the statistics severely mask the reality ... (and that)... parents and physicians conceal many cases of childhood and adolescent suicide, or report them as accidents" (McGuire \& Ely, 1984, p. 19). An undetermined, but "large proportion of childhood lethal accidents" are unrecognized or unreported suicides (Adams \& Fras, 1988, p. 543).

Using rates of suicide as the basis for comparison, "childhood affords a degree of protection that has been 
unaffected by the considerable changes in social environment experienced over the past century" (Shaffer \& Fisher, 1981a, P. 550). Children who do attempt suicide (Kienhorst et al., 1987) experience environments characterized by problems. "However, we still do not know why most of the children living in such a situation (or a more difficult one) do not make a suicide attempt and the remainder do" (p. 165). Shaffer and Fisher (1981b) claim that

what needs to be explained is not some factor which predisposes children to suicidal behavior but $r$ ather the reverse. Given that beliefs in the reversibility of death are common and that suicide is uncommon in childhood it cannot follow that one finding explains the other (p. 97).

Addressing these questions within the parameters of this study, this thesis asserts that children resort to suicide because their protective psychological mechanisms-ego defenses--fail them during periods of chronic stress or intense stress. This thesis is not a new one; it was stated by Schechter in 1957: "It is when the degree of tension is extremely high and the defense mechanisms break down or become ineffective that suicide or suicidal equivalents may appear" (p. 132).

The intention of this project is to explain how manifest suicidal behavior occurs using the approach of psychoanalytic developmental object relations theory. This thesis thus addresses aspects of ego-defensive functioning-that which protects from self-destructive actions and that which permits self-destructive actions.

Through an examination of suicidal behavior in 
latency-age children from a psychoanalytic developmental object-relations approach, this thesis contends that the susceptibility to suicidal behavior becomes part of the child's ego organization during the first three years of development. The precipitating environmental events to suicidal behavior, inordinate stress and loss, confront an ego-organization which lacks the capacity adequately to protect the child from self-destructive actions. Suicidal behavior is thus construed as a consequence of a process of disturbed development rather than as a discrete, impulsive act brought about by a sudden, massive regression in ego functioning.

The term development includes both normal and psychopathological development and refers to psychological changes and functioning which attend physical maturation. Within this conceptualization of development, "the ego is to be regarded as the process of organization per se.... the ego is defined by its functioning" (Blanck \& Blanck, 1979, pp. 8-9). That is,

the ego is seen primarily as enabling the regulation and adaptation of the personality to external reality.... has a range of functions, including observation, reality testing, rational thought and perception.... functions largely within the conscious domain except for its defence mechanisms which are unconscious processes (Walrond-skinner, 1986, pp. 108, 110).

Psychopathological development refers to modifications of the ego. Deviant development describes aspects that "depart too early from the normal"; distorted development describes the "internalization of faulty perceptions of self 
and object representations" (Blanck \& Blanck, 1974, P. 93). As an example, Aber and Allen (1987) comment:

Dne general interpretation of the effects of maltreatment is that it slows children's rate of socioemotional development. An al ternative position is that maltreatment does not lead to developmental lags but rather to qualitative differences in development. Recent research suggests that these two positions may not be mutually exclusive but, rather, may work in complex, sequential fashion.... For some populations of children at risk, initial developmental lags may become structuralized over time into nondevelopmental, qualitative differences in developmental pathways (p. 412).

This thesis thus contends that deviations or distortions in emotional development predispose some children to suicidal behavior, and further, that the primary and critical areas of development are the functions of object relations and the psychological mechanisms of ego defenses. These children's self-protective mechanisms are unstable and unreliable. Alternatively, relatively successful completion of the tasks of the first three years results in a latency-age child with an ego organization capable of mastering the developmental tasks of this age, including the capacity for self-protection.

In response, then, to the question why more latencyage children do not kill themselves, the thesis proposes that the "structure of latency" (Sarnoff, 1987) affords a degree of protection for children who have successfully completed the tasks of emotional development. The "structure of latency," a categorical term which describes the ego-organization of the child between the approximate ages six through twelve, may also fail to protect the child 
whose early emotional development includes deviations or distortions. That is, the child's protective psychological mechanisms are tentative or fluid, and protection through ego regression is insufficient. The child loses the protective and relative safety of latency, and suicidal behavior ensues.

Although an inimical environment by itself provides an inadequate explanation for suicidal behavior, a description of environmental phenomena is necessary to account for external stresses which contribute to it. Living in a family means developing within a family's system, and particular systems foster deviations or distortions in development as the child adapts to them.

The organization of the thesis is as follows: Chapter I Includes a classification and definition of psychoanalytic developmental object relations theory, including criticisms, followed by a description of the separation-individuation process and phase-appropriate reliance on particular psychological mechanisms. Chapter I I elucidates the structure of latency, including reactions to $10 s s$ and conceptions of depression. Chapter IV reviews the literature on childhood suicide and interprets findings in order to articulate a theoretically sound conceptualization of suicidal behavior in latency-age children. Chapter $V$ presents the conceptualization in the form of a model. 


\section{DEVELOPMENTAL OBJECT RELATIONS THEDRY}

Two approaches direct this thesis. Developmental psychopathology sets forth the general framework and psychoanalytic developmental object relations theory determines the conceptual presentation.

\section{DEVELOPMENTAL PSYCHOPATHOLOGY}

The principles of developmental psychopathology are stated in the following propositions set forth by Sroufe and Rutter (1984) in "The Domain of Developmental Psychopathology": 1. Holism: Understanding the meaning of behavior requires consideration of its entire psychological context; 2. Directedness: Over time one takes a greater role in constructing the environment; 3. Differentiation of modes and goals: Over time one becomes more flexible and organized; 4. Mobility of behavioral functionsz Behavior manifested early in development is integrated into behavior manifested later in development; 5. Problems of continuity and change: Human development proceeds along a lawful course, and a connection exists between "early adaptation and later disorder" (pp. 20-22). Deviations from the normal 
course of development define disordered behavior (Sroufe \& Rutter, 1984, P. 19) or "deviations that lead to pathological development" (Blanck \& Blanck, 1974, P. 71 ).

An essential principle of developmental psychopathology is called the "orthogenetic principle" (Cicchetti \& Schneider-Rosen, 1984). It asserts that "development proceeds from global and diffuse states, by means of differentiation and integration, to states of articulation and hierarchical complexity" (p. 11). Two others are stated by Garber (1988): "Development is a series of behavioral reorganizations around specific salient developmental issues.... Developmental issues are broadly integrative and cut across affective, social, and cognitive domains" (p. 32).

The successfully functioning child is a competent one, one who uses "environmental and personal resources to attain a satisfactory, age-appropriate adaptation ... (by successfully resolving)... the developmental tasks salient to his or her age" (Cicchetti \& Schneider-Rosen, 1984, p. 8). Conversely, maladaptation (Garber, 1988) is defined in terms of incompetence or deviation in the complation of devel opmentally-defined tasks or in terms of failure to deal with phase-appropriate experiences.

\section{DEVELOPMENTAL OBJECT RELATIONS THEORY}

In "Developmental Psychopathology: A Nine-Cell Map of 
the Territory," illustrated in Figure 1, Cowan (1988) categorizes developmental object relations theory into two of nine cells, the "Individual Psychological Level of Analysis ... Internal Views: Cell 4" (p. 13) and the "Relationship Level of Analysis.... Internal Views: Cell 7" (p. 18).

Internal External Interactive

Physical/Biological

Cel1 $1 \quad \operatorname{Cel} 12$

Cel13

Individual /Psychological

Cell 4

Cell 5

Cel1 6

Rel at i onship

Cell 7 Cell 8

Cell 9

Figure 1. Nine explanations of stability and change. Adapted from Cowan (1988).

In cell 4, Cowan places humanistic psychology with its emphasis on "innate inner forces pushing individuals toward self-actualization" with psychoanalytic psychology with its emphasis on "stage changes in the locus of pleasure ... driven by underlying biological development" (p. 13). Adequate parenting ensures "development toward increased levels of adaptation" (p. 13).

Cowan criticizes this cell because he holds that "external forces do interfere with the child's development," and these theories consider events as "distal causes of 
psychopathology, setting in motion a chain of events resulting in an internal proximal cause of stability and change" (p. 13). That is, the child reacts to disruptions with anxiety, which in turn "mobilize defenses, and unbalance the relative influences of id, ego, and superego on behavior" (p. 13).

Regarding cell 7, Cowan includes the terms working models and relationship schewes along with object relations to denote the beginning development of symbolic relationships within the child during its first year. object relations theorists emphasize the "earliest bond or attachment between caretaker and child as laying the essential foundation for later child development and adaptation" (PP. 18-19). He notes the work of American researchers conducting inter-generational studies whose findings support "the hypothesis that the quality of early and continuing parent-child relationships may be important in the child's later progress through normal developmental stages or tasks" (p. 19). He also notes that studies examining the relationship between disruptions in parentchild bonds and later anxiety, depression, and aggression "have not yet led to clear-cut results" (p. 19).

Criticisms of the two cells come from Cicchetti and Schneider-Rosen (1984). Proposing a transactional model of childhood psychopathology, they label the internally-focused models "early experience" and "main-effects" (p. 15) which 
they consider "too simplistic for most of today"s investigators" (p. 15). They claim the models are "deficient" because neither clinical observation nor empirical research affirms "a strict cause-effect determinism," because they disregard the person's active responses to nocuous causes, because they fail to account for variations in time prior to the manifestation of symptoms, and because a stress on factors predisposing one to depression deemphasizes later experiences which may militate against pathology or contribute to more serious pathology (pp. 15-16).

From a psychoanalytic position, Brody (1982) indirectly criticizes object relations theory by criticizing the 1 andmark study conducted by Mahler, Bergmann, and Pine (1975). She contends that it lacks validity because of defects in methodology, metaphoric or adultomorphic interpretations of behavior, and bias in findings. She considers that a child's sense of "autonomy, or independence, or individuation" could be assessed more accurately around age six than between ages three and four because of the developmental tasks occurring between three and $\mathrm{si} \times(\mathrm{p} .571-572)$.

Despite these criticisms, contemporary object relatians theory possesses a similar rationale as the transactional model of childhood psychopathology. It seems applicable to the "internal" views taken here (cicchetti * 
Schneider-Rosen, 1984): "A transactional model views the multiple transactions among environmental forces, caregiver characteristics, and child characteristics, as dynamic, reciprocal contributions to the events and outcomes of child devel opment" (p. 19).

The formulations of contemporary object relations theory derive from clinical observation and empirical research of infants and toddlers. Its utility is stated by Brody (1982):

It is during infancy that potentials may be observed for a balance of active and passive aims, qualities of object relations and of beginning - identifications, function pleasures, or for the lack of these. The staying power of these potentials builds habitual ways of responding to inner and outer events that underlie health or illness. They reflect nascent character qualities (p. 582).

Fraiberg (1987) adds that "the period of greatest vulnerability with respect to later development is in the period under two years of life" (p. 18). Children deprived of "prolonged intimacy with a nurturing person.... show varying degrees of impairment in the capacity to attach themsel ves.... seem to form their relationships on the basis of need and satisfaction of need" (pp. 18, 21). Studies of deprived infants identify "disorders of iapulse control, particularly in the area of aggression" (p. 19). She concludes that pathological families fail to provide significant attachments because a depressed or addicted or psychotic caretaker (mother) is an absent one (p. 19). 
Description of the Theory

A description of psychoanalytic developmental object relations theory, Cowan's cell 7, relationship levels of analysis, internal views, follows.

Kernberg (1980) defines object relations theory as

an integral part of contemporary ego psychology.... it represents a special approach or focus within the structural viewpoint that links structure more closely with developmental, genetic, and dynamic aspects of mental functioning.

Bl anck and Blanck (1986) present

the term psychoanalytic developmental object relations theory. .... In psychoanalytic parlance an object is a person other than the subject. But psychological 1 ife does not begin with perception of self and other. Even when perception begins, self and object images are merged. Contemporary ego psychology describes the first three years of life as a dyadic experience during which the merged images separate out gradually into more or less distinct and stable self and object representations. This suggests that even the term object relations theory is somewhat of a misnomer; it should be self and object relations theory. This would reflect the psychology of the early days, weeks, and months of li fe (pp. 1-2).

\section{Hamilton (1988) explains:}

- An object is a person, place, thing, idea, fantasy, or memory invested with emotional energy (love or hate or more modulated combinations of love and hate). An external object is a person, place, or thing invested with emotional energy. An internal object is an idea, fantasy, or memory pertaining to a person, place, or thing (p. 7). 1988):

The concept of self is more difficult (Hamilton,

The ability to see objects as different from one another precedes the ability to appreciate self as a separate entity.... Self refers to conscious and unconscious mental representations that pertain to one's own person.... whereas object sometimes means 
an external person, place, or thing and sometimes an internal image, self always refers to an internal image. According to this usage, someone viewed by an outside observer is not a self, but a person. The self is private (pp. 9, 12).

Pine (1985) holds that

what defines contemporary object relations theory is ... a view of mental life that is organized around self and object representations and their relations and repetitions in addition to an organization of mental 1 ife around drive, defense, and conflict (p. 61).

Object relations, then (Hamilton, 1988) are

the interactions of the self and internal or external objects.... An object relations unit is a self-representation and an internal object connected by a drive or affect. When the distinction between self and object in an object relations unit is unclear, it is called a self-object. Symbiosis is the first and most thoroughly undifferentiated sel f- object out of which other object relations evolve (pp. 13, 15, 20).

Object relations theory (Blanck \& Blanck, 1986) "is far more than the simple action of the environment upon the child; it is infinitely more complex, involving action, reaction, and interaction" (p. 15).

The "organizing principle" (Blanck \& Blanck, 1979) of contemporary object relations theory considers that

major aspects of intrapsychic and behavioral 1 ife are organized around processes of separation and individuation.... ego structure per se evolves out of these processes as they encompass the impact of the instinctual drives. Differentiation of self images from object images is an essential part of the process of ego organization.... the ego develops the function of object relations as ego structure derives simultaneously from object relations ( $p$. 21). 
They add that "the self and object images, merged at first, separate out gradually as the infant sorts out that which is self from that which is other." Assisting this accomplishment is physical maturation and, initially, the force of the aggressive drive (Blanck \& Blanck, 1986).

The mother-infant dyad constitutes the environment out of : which "self and object images are built out of myriad daily affective experiences that begin on day one or before" (Blanck \& Blanck, 1986, p. 50). They consider a wellmatched mother-child pair one in which "a child who responds to a responsive mother. A less-responsive child fortunately matched with a mother who extends herself. A child who can reach out to a less responsive mother, forcing her to respond" (1986, pp. 51-52). A poorly matched pair includes "a child who gets little or no response even upon reaching out....(or)... a child unable to make a connection with the mothering person no matter how much she reaches out" (p. 52).

Separation-individuation, whose primary task consists in "the development of relatedness to a significant other, with the achievement and maintenance of self-other differentiation (Pine, 1985, p. 46) proceeds in stages. The stages were distinguished by Mahler, Pine, and Bergman in their ten-year observational study of normal infants and children and their mothers and explicated in The Psychological Birth of the Human Infant (1975). 
Normal autism. The first phase of the growth process, from birth to two months, is labeled normal autism. Hamilton (1988) describes it: "The infant forms a more or less closed psychological system and is cloaked in the reverie of a sleeplike state. The newborn's psychological withdrawal approximates the insulation of intrauterine 1 ife" (p. 36). Based on results of infant research, Blanck and Blanck (1986) hold that "new evidence shows only that there is alertness and reception of input earlier than supposed" (p. 55). The theoretical basis for their conclusion is that "normal infants possess apparatuses that are potentiated upon contact with the average expectable environment because the neonate is at the peak of adaptive capacity" (p. 55). Concurring, T. M. Horner (1988) holds that "the original psychic condition of 1 ife is one of sensory, perceptual, and cognitive distinctions" (p. G).

Pine believes the utility of the normal autism concept is its provision of a "contrast point for a later period when the infant's investment in the mothering one is clearly relatively more in evidence" (p. 48).

Should early connection fail through the mother's or infant's shortcomings, "innate apparatuses are not quickened at the age appropriate time. They remain as unrealized potential and may not be quickened belatedly because, for some functions, timing is of the essence" (Blanck \& Blanck, 1986, p. 55). 
Normal symbiosis. In the normal symbiotic phase, from two to six months, the infant "begins to behave as if his mother and he were part of the same 'omnipotent' system--a dual unity within one common boundary" (Hamilton, 1988, p. 38). A "two-person relationship" does not yet exist, for differentiation is just beginning through early ego functions--"memory, cognition, motor coordination"-which enable rudimentary organization and the initial sense of a self (p. 38).

The child's "unfolding ego functions" are enhanced by a loving, responsive parent, for "if the child does not have such a relationship, if his mother does not adequately receive his cues about his needs and respond to them, the child's genetically programmed ego functions fail to develop" (Hamilton, 1988, p. 38). As evidence of this assertion, Hamilton cites the studies conducted by Spitz (1965), in which children who had lost their mothers and ended up in foundling homes lacked sufficient human contact and interaction. Although they received enough food, some of them eventually died.

Even within optimal environments, infants experience unpleasant sensations and events which distress them (Hamilton, 1988, p. 39). Developmentally, these experiences facilitate the early distinctions between self-images and object-images in that "pleasure and pain, good and bad, 
become a second polarity around which the child organizes its world, along with the self-other polarity" (p. 40).

The pleasure and pain polarity (Blanck Blanck, 1979) becomes associated with caretakers in the infant, that is, the gratifying, "good" parent provides pleasure, the "bad" parent permits the experience of distress, but the experiences remain separate. "Good" experiences of sel $f$ and object images must predominate over "bad" ones for normal affect development. Because the "phase-specific requirement is for union," a premature differentiation of separation served by aggression will interfere with the symbiotic union and its requirement for primarily "good" experiences (pp. 56-57).

Separation-individuation. The separationindividuation phase, from 6 to 24 months, consists of three subphases. Entry into separation-individuation (Blanck \& Blanck, 1979) provides "myriad opportunities ... for enhancement (or impairment) of self-esteem.... The very experience of adequacy, that is, optimal fulfillment of the developmental purpose, adds to the sense of self-valuation" (p. 59). Pine (1985), maintains that meeting the tasks of this stage is critical for cognitive development, for the infant's awareness "of separation is anchored in perceptual reality, which leads to an organization of stimuli and of memories around the self-other distinction" (p. 247). 
According to Blanck and Blanck (1986), separation occurs through the stage-appropriate predominance of the aggressive drive and activity, interest in persons besides the mother, and the mother's letting go her own need for union with the infant.

The first subphase, hatching, or differentiation, fron 6 to 10 months, is marked by the infant's appearance of alertness, purposeful actions, and "displays an increasing interest in the appearance of other people as opposed to his parent" (Hamilton, 1989, P. 41). Mahler (1986) considers the process "a gradual ontogenetic evolution of the sensoriun--the perceptual-conscious system--which leads to the infant-toddler's having a more permanently alert sensorium, whenever he is awake" (p. 224). Children who benefitted from an optimal symbiotic phase display confidence and curiosity in the differentiation subphase. Those who have not display distrust and excessive anxiety around strangers.

In the practicing subphase, from ten to sixteen months, the infant "gradually emerges from differentiation" (Hamilton, 1988, p. 43). The "early practising phase" (Mahler, 1986) is characterized by the infant's earliest ability to move away physically from mother by crawling, climbing and righting himself, yet still holding on" (p. 226). The child and mother develop a specific bond in which 
the toddler remains close to the mother, who provides security, while exploring the environment.

In the practicing subphase proper, the "thrust" to separate (Blanck \& Blanck, 1986, P. 53) serves "the rapidly growing autonomous ego and its functions; the child seens intoxicated with his own faculties and with the greatness of his world" (Mahler, 1986, p. 228). Mahler considers the child's elation during this subphase partly the thrill of separation combined with the reassurance of connection.

In their study, Mahler and colleagues noted that the children became low-keyed only as they became aware that their mothers were absent from the room. Children then displayed a decrease in motility and less interest in their surroundings; they "appeared to be preoccupied once again with inwardly concentrated attention, with what Rubinfine (1961) called "imaging" (p. 229). During these times, children responded with tears to attempts by the staff to confort them, and required the mother's presence and reunion to return to their previous state. The children's behavior while separated from their mothers seemed like a "miniature anaclitic depression.... the child's effort to hold on to a state of mind ... the 'ideal state of self" (p. 229).

Rapprochement, the third subphase in the separationindividuation process, takes place from about sixteen to twenty-five months. Mahler (1986) notes the toddler's 
awareness and use of separateness along with increased concern for her availability in relation to the practicing subphase. The child possesses "an increasingly clear differentiation between the intrapsychic representation of the object and the self-representation" which involves relinquishing the sense of grandiosity (pp. 230-231). Rapprochement thus describes "a process of restoring positive equilibrium following perturbations" in the toddler-parent relationship, a process of effectively dealing with frustrating interactions and "re-attaining basic love and security" (T. M. Horner, 1988, P. 13).

The child reacts to the loss of grandiosity with tantrums. These represent the hurt from "rejection by the old symbiotic partner" (Hamilton, 1988, p. 47) and "defense against the depressive realization" (B1anck \& Blanck, 1979, p. 61) made possible by the attainment of a greater degree of reality testing ( $B 1$ anck \& $B 1$ anck, 1986).

Mahler (1986) considers the rejection experienced by the child as "fear of loss of love" and that it takes place while the child yet fears the loss of the object (p. 231). These fears produce wide emotional swings in which the child treats the parent as "all-good or all-bad" depending on the child's mood (Hamilton, 1988, p. 48).

A. J. Horner (1984) explains:

- The rapprochement period marks the shift from normal, developmental splitting to the capacity for ambivalence toward a single object, although the consolidation of this capacity does not come about 
until toward the end of the separation-individuation process (p. 139).

The main task of this subphase is a delicate one (Blanck \& Blanck, 1979), for the toddler must acquire more realistic expectations of the self and others. The child must possess a balance of self and object images in order to sustain independence and self-esteem while maintaining predominantly good feelings toward the parents.

Adequate self-esteem is called "rapprochement adequacy" (Blanck \& Blanck, 1979, p. 61). Its acquisition follows the child's capacity to value itself by applying to the expanding self-image the admired qualities of the object-image through selective identification.

The $r$ isk attending this subphase involves a loss of self-esteen and establishment of a "basic depressive affect through failure of maternal response" (Blanck \& Blanck, 1974, p. 72). This constitutes object loss and "leads to denigration of both self and object" (p. 72). They provide an example:

The mother died at a stage in the child's development when separation-individuation had not yet been completed, when object loss would feel like loss of part of oneself, when disappointment in the failure of the mother's omnipotence would result in disillusionment, aggression, and loss of selfesteem, when separation anxiety would be severe, when the capacity to mourn and thereby overcome the loss was not yet available (pp. 272-273).

Another danger involves difficulty modifying or limiting aggression because the child's love for its parent is unable to overcome the experiences of frustration when 
they predominate (Fraiberg, 1987). The disruption of the infant-parent attachment "can have permanent effects upon the later capacities of the child to love and to learn" (p. 440-441).

The fourth stage of separation-individuation, object constancy, takes place from 24 to 36 months and beyond. Object constancy (Hamilton, 1988) "means the ability to hold a steady image of the object, especially the mother, whether she is present or absent, gratifying or depriving" (p. 53). It is "the capacity to recall good feelings about a parent while seriously disappointed in them" (p. 55). This capacity allows the toddler to comfort itself through the internal representation of the caretaker and reduces physical dependence on the caretaker's actual presence. This developmental gain serves the toddler's autonomy (Pine, 1985).

Recalling good feelings about the parent and using them for self-comfort permit another developmental gain, the capacity (Pine, 1985) "to unite all aspects of the mother, the good and the bad, in one concept" (p. 106). In normal development, this capacity is gradually achieved by age three. The child then can "temper rage and disappointment by connecting them with memories of the loving as well as the frustrating actions of mother" (Pine, 1985, P. 106). The toddler uses these abilities to maintain autonomy while 
retaining closeness, to regulate longing and $r a g e$, and eventually to regulate self-esteem.

The "fusing the loving and hating feelings" (Pine, 1985, p. 84), integrating "good and bad aspects of selfrepresentations and good and bad aspects of objectrepresentations," bringing together "all-good and all-bad self-images" (Hamilton, 1988, p. 107) describe the task of development during object constancy. This accomplishment allows the consolidation of identity with the recognition of a variety of characteristics (Hamilton, 1988).

Emotional object constancy marks the beginning of "self constancy" (Hamilton, 1988) which advances intentional activity even while experiencing mild frustration (p. 55). Individuation, the process of creating a self, has begun in earnest as the toddler assumes characteristics which define itself (Pine, 1985); it continues throughout life as one progresses through later stages of development (Hamilton, 1988).

With attainment of object constancy, the fear of the loss of the love of the object replaces the fear of object loss (Hamilton, 1988).

According to Blanck and Blanck (1986), the achievement of object constancy requires a predominance of gratifying experiences with the caretaker over frustrating experiences. A predominance of negative experiences interferes with the coalescense of gratifying and frustrating object images into 
a unified person, and consequently interferes with the establishment of a unified self through the integration of various self-images. Thus, failure to achieve developmentally appropriate object constancy results in a continual "search for good self and object images ... perhaps throughout 1 ife" (p. 59).

Confusing, frustrating environments disrupt the integrating functions of the child's ego because the "capacity to compare and contrast emotional experience fails to develop.... they remain stuck in a split, all-good and al1-bad self- and object-experience" (Hamilton, 1988, p. 110).

Blanck and Blanck (1986) summarize seven functions of object relations: (1) the provision of safety feeling in infants for trust, adaptation, and coping; (2) establishment of internal regulatory functions for self-limiting behavior and socialization; (3) promotion of ego autonomy "through comfortable acquisition of functions of the object relations with minimal conflict" (p. 67): (4) serving as a model for character formation through selective identification/internalization of external objects to form sel fepresentations; (5) promotion of superego development through internalization of parental prohibitions, demands, and values; (6) provision of an 'ego ideal', internalized qualities of objects by which one measures the self in character formation; (7) enforcing resolution of Dedipal 
wishes (through "love for the parent of the same sex" Ip. 281) as identification intensifies and sexual wishes are repressed, thereby enabling the child to enter latency (pp. $62-70)$

In a case study, Kennedy and Moran (1984) trace the developmental history of a four-year-old boy, Tom. In the first weeks of his life, he received minimal care. In the first year, he experienced a predominance of painful experiences. His treatment resulted from his mother's depression, which resulted in rough handling and sustained periods of distress. The authors consider these experiences as Iaying "a foundation for an aggressive taint to his relationship to self and object" (p. 203).

In his second year, Tom had many accidents. These resulted from his unrestrained impulse control through his mother's inability to set limits in a secure way. At a critical period of his development, Tom was "prevented from sharing in the illusion that his mother could protect him from painful experiences" (p. 203). He also showed an "apparent inability to be loving toward his mother ... later understood as a defensive stance against a fear of loss of her love" (p. 204).

By his third year. Tom's self-image was of an unsafe and unloved person. This image increased his fear of the loss of his mother. His aggressive actions escalated in the form of attacks on his baby sister, and he felt rejected and 
condemned by his mother. He internalized his mother's condemnations in his developing conscience, and experienced guilt when he hurt his sister. Consequently, he hurt himself rather than his sister; hurting himself got his mother's attention and concern, that is, her love. It also amounted to an expression of his fear and dislike of his aggressive actions. Self-injury was part of his defense against his anger from his feeling disappointed and rejected. Self-injury and the experience of pain was the method Tom employed to get "closeness" from his mother (p. 212).

Satisfactory progression through the separationindividuation process through the receipt of primarily gratifying interactions with caretakers results in a child considered competent. The child can evoke loving images of a person while frustrated with the person and can rely on these images for comfort. The child possesses the beginnings of a realistic self-image, adequate self-concept, and consequent self-confidence, and can persist with purposeful activity. The child's feelings toward itself and others are positive and include a healthy self-esteen. The child feels safety in itself and trust in others, has internalized the basic regulatory functions for selfcontrol, socialization, and conscience, and can function autonomously for its age, that is, can adapt to situations and cope constructively with frustration and disappointment. 
As illustrated by the case of Tom, a child whose movement through the separation-individuation process has taken place through primarily negatively tinged experiences with caretakers lacks the capacity to integrate disparate sel $f$ and object images into a single, whole other person or self. Without the provision of safety from the environment, the child lacks trust in itself and others and a secure sense of self-esteem and self-confidence. The child perceives self and others as all-good or all-bad, that is, split object relations.

Because the drive to separate predominates over the drive to unite, the child lacks the basis of self-esteem and self-nurture and the affects of frustration, disappointment, anger, and hostility dominate emotional functioning. The child has problems in self-control and regulation and difficulty relating to others. Along with these difficulties, experiences of object $105 s$ and fear of the loss of the object's love produce depressive reactions defended against by rage. The child is susceptible to depression. Although he or she establishes an emotional equilibrium, it is brittle or tenuous and disturbed through disappointment with an attendant loss of self-esteen.

The child may blame itself when unloved by parents and develop "a schematic attitude" of a "degraded self-schema" in which the child believes the self is "unlovable" (Horowitz, 1988, p. 47). 


\section{Psychological Mechanisms}

This section defines and explains the utility of particular terms expressed previously, such as identification, internalization, repression, and splitting. The purpose of this section is to show that the acquisition and use of these mechanisms contributes to the child's development and adaptation.

Integration and Differentiation. Object relations theory posits the complementarity of these functions which "pervade development from the beginning and persist throughout life" (Hamilton, 1988, p. 60). Bringing two mental elements together, such as "perceptions, memories, representations, emotions, ideas, movements" (p. 60) is the integrative function. Setting apart two mental elements is the function of differentiation. For example, self-other differentiation is the result of the separationindividuation process (Pine, 1985).

These processes can be disrupted in early development (Hamilton, 1988):

by strong emotions in infants.... Longing, frustration, excitement, and contentment interfere with and alter the integrative ego functions, leading to projection, introjection, splitting, and projective identification. These later mental processes are sometimes called defense mechanisms because they protect the self-image from a catastrophic loss of a sense of well-being in the face of overwhelming frustration. Mental defenses attempt to insure the integrity of a sense of self and often provide the emotional richness and complexity of our lives (p. 63). 
Projection. Projection is a differentiating ego function involving the attribution of one's own unwanted quality to another person with a similarity to the quality, but in doing so exaggerates and distorts the quality. The infant in the symbiotic phase of development is thought to associate the experience of pleasure as self and the experience of pain as other. The self-mother unity is retained as good while "dual unity" is projected as bad. Projection is thus a form of confusion between sel $f$ and ob ject (Hamilton, 1988, p. 67).

Incorporation, introjection, and identification. These functions are considered "taking in processes" (Hamilton, 1988, P. 68). As such, they mean processes "whereby functions of the object representations are transferred to the self representations" (Blanck \& Blanck, 1986, p. 22). Distinctions among these functions depend on the infant's or child's level of development or structuralization, and that, according to Blanck and Blanck, the term internalization "obviates straining for fine distinction" (p. 61). Their import (Blanck \& Blanck, 1986):

Structuralization, differentiation, and internalization are continuous processes. The young infant merges with the gratifying object-imagesexperienced-as-part-of-the-self-images; the separating-individuating toddler "absorbs" or transfers aspects of the object representations to the ever-differentiating self representations; the oedipal child begins to organize the precipitate of parental values ... into a value system of his or her own (p. G1). 
Incorporation takes place (Hamilton, 1988) "prior to the development of clear self-other boundaries" (p. 68). Chessick (1985) considers it a "primitive kind of interpersonal relations fantasy.... a form of fantasied 'ob ject relatedness" "(p. 65).

Introjection (Hamilton, 1988) supersedes incorporation because the infant can distinguish between the self-image and object-image rather than merging the object-image with the self-image. The object-image is "sufficiently vivid to have emotional power in the internal world" (p. 69). It is thus (Chessick, 1985) "a change in psychic organization and in the psychic status of an object representation" (p. 66).

Called an introject (Chessick, 1985), the internalized object-image is created as a response to "severe ambivalence or more or less disappointment in an attempt to modify distressing relations with the external object." Doing so reduces the influence of the object on the self (p. 66). An introject (Horowitz, 1988) "is a critical 'figure' who seems to speak. in the mind in the role of someone else" (p. 138), such as a parent.

With attainment of object constancy, introjection modulates into identification through the transformation of introjects into new forms of mental representations (Hamilton, 1988).

Of the internalizing processes, identification is the most mature and thought of as modeling, initially on 
parents. This mental process occurs automatically, usually unconsciously, promotes emotional growth and adaptation, including "adaptation to a feared or lost object." In this process, the individual makes aspects of another his or her own (Chessick, 1985, P. 65).

The growth-promoting and adaptive functions of identification describe an attribute of it termed selective identification, the "transfer of functions of the object representations to the self-representation" (Blanck \& Blanck, 1986, p. 121).

A protective, albeit problematic, aspect of identification is termed identification with the aggressor; it is employed under stressful circumstances, as in abusive situations:

When a child is hurt, he has an increased need for those upon whom he depends. Consequently, he may cling even more fiercely to the very parent who harms him. The need for closeness leads the child to firmly introject the abusing parent and then identify with the powerful figure. The child no longer experiences himself as small, helpless, and hurt, but as big, powerful, and strong (Hamilton, 1988, p. 117).

This position enhances "survival potential" (Horowitz, 1988), but at the risk of "making others victims to avoid the victim role for self" (p. 105).

Projective identification. Projective identification describes a mechanism that combines elements of identification and projection. This mechanism operates by the projection of an aspect of the self onto the object. 
The purpose is to "control the projected aspect of the self in the object" (Hamilton, 1988, p. 87). The attempt at control indicates an awareness that on some level what is projected is a part of oneself (Hamilton, 1988).

The initial attempts of the symbiotic child to differentiate self from object constitute partial attempts, similar to the integration of self-images and object-images. As the child moves from symbiosis into separationindividuation, the distinction between self and object becomes clearer. Children "attribute their own feelings to their parent and try to control those feelings in that parent" (Hamilton, 1988, P. 95). The feelings projected range from hostility to affection, such as the sharing of happiness and expressing concern manifest by rapprochement subphase children (Hamilton, 1988).

The combination of projection and introjection become used for "the acquisition of information for inclusion in the superego demands" (Sarnoff, 1987, p. 337). If a child projects hostility onto a parent, the child will introject images of a hostile and punitive parent. The child's selfimage will include elements of hostility and aggression. The child also projects interpretations onto the environment and uses resulting information to adjust self-image and behavior. That is, environmental influence, reality, and memory operate in the service of emotional and behavioral expectations (Sarnoff, 1987). 
Sarnoff (1987) considers that the extent to which reality experiences can promote corrections of perceptions depends upon the rigidity that prior beliefs are held. The more investment in existing beliefs ("narcissistic libidinal energies") the less will reality experiences serve to modify them. This results in rigid self-images and environmental expectations whose outcomes include "pathological patterns" (pp. 337-338).

Splitting. Splitting (Blanck \& Blanck, 1979) is a "feature of the developmental phase before the attainment of the ability to tolerate that good and bad object images refer to the same whole person" (p. 144). It is

the active keeping apart of contradictory internal experiences of the self and of significant others. These contradictory elements remain conscious, but are separated in time or space, and do not influence one another (Hamilton, 1988, p. 76).

Splitting transforms into (Pine, 1985) "a defense that functions to preserve the representation of the love object from the destructive forces of hate but simultaneously permits the luxuriant growth of hate, unmodified by cbecause split off from) love" (p. 84). "Often the same person will be alternately idealized and devalued" (Horowitz, 1988, p. 195). Thus, "only one set of memories is available to experience at a time. Self-coherence is protected at the expense of developing realistic working models" of the self (Horowitz, 1988, p. 107). 
This chapter categorizes developmental object relations theory within the parameters of developmental psychopathology. It then states criticisms of the theory followed by a description of it by contemporary theoreticians, including the development of psychological mechanisms.

The explication of both the separation-individuation process and the acquisition and utilization of psychological mechanisms has attempted to show how these integrating and differentiating functions unfold as interrelating components of object relations development in both normal and distorted development. It has attempted to demonstrate how early disturbances in object relations create a child with a tenuous emotional equilibrium, one which is susceptible to depression through object loss and through difficulty integrating good and bad aspects of persons into consistent object-images and a stable self-image. The result is a child with low self-esteem dominated by hostile affects who relies on less developed psychological mechanisms in the process of devel opment.

The following chapter defines latency and describes emotional development during latency. 


\section{CHAPTER I I I}

\section{LATENCY}

In their overview of latency, Shapiro and Perry (1980) reviewed findings from developmental psychology although they write from a psychoanalytic perspective. They hold "that latency is biological in origin and relatively imautable in the march of development" (p. 163). They cite the "functional changes in the child"s neurobiological, perceptual, and cognitive development" which come together around age sevens these changes. "in the organization of mental 1 ife and their dynamic concomitants provide latency with the behaviors that characterize this stage" (p. 162).

They also cite "perceptual-postural maturation.... temporospatial orientation.... and cognitive changes at seven" (pp. 168-170). Regarding cognitive changes, they note research relating cognitive maturity and moral judgaent, cognitive mediation between thought and action, and the demonstration of "reasoning, insight, and inferential behavior" ( Pp. 170-173). "Mediated," that is, "more structured," thought processes, the secondary process, are replacing "original associational" thought processes, 
the primary process, because the "energies underlying them are relatively bound" (pp. 173-175). These changes account for latency's onset rather a "biphasic growth of the sexual drive" (p. 173).

A greater degree of autonomy marks the normal latency child. This permits less emotional dependence on family and an increased capacity to exercise control over the environment. Related developmental achievements include the ability to delay action and to inhibit drive impulses, including sexual impulses.

Secondary thought processes allow the child to obey internal cues such as prohibitions on behavior. The capacity to exercise the superego (conscience), that is, "the replacement of outer control by inner control and the consequent propensity toward conflict may ... have a material base in the establishment of neurodevelopmental structure" (p. 176).

Sarnoff (1987) describes the developmental period of latency as follows:

Latency is here used to describe a period of dynamic defenses during which the child experiences a complex reorganization of the defensive structure of the ego. A state of good behavior, pliability, and educability is maintained as a result of an equilibrium between defenses and drives. This state is possible because of the evolution and ontogenesis of mechanisms of defense that can produce it. It is not obligatory, however, and is facultatively present at the discretion of the culture in which the individual lives ( $p$. 5). 
Defense mechanisms undergo developmental alterations in latency which are adaptive. For example, fears of persecution are defended against by projection. Repression lacks the strength it will have later in development. The child's egocentrism strengthens denial (Sarnoff, 1987).

Sarnoff lists the defenses of sublimation Creplacing "an unacceptable wish with a course of action that is similar to the wish but does not conflict with one's value system" [Horowitz, 1988, P. 195]); obsessive-compulsive activities (e.g, stamp collecting); doing and undoing cunconsciously erasing a consciously intolerable action, "thought, wish, impulse" [Laughlin, 1983, p. 428]); reaction formation creplacing a "warded-off idea or feeling ... by an unconsciously derived but consciously felt emphasis on its opposite [Horowitz, 1988, p. 194]); and repression ("withholding from conscious awareness an idea or a feeling" [Horowitz, 1988, p. 195]) whose "activities produce the psychological state of calm, pliability, and educability.... They help the child to adapt to a world requiring social compliance and the ability to acquire knowledge" (p. 6 ). They also "provide for the interposition of modifications of aggression" (p. 5).

The child capable of entering the state of latency can utilize these relatively more advanced defenses for adaptation and rely on them to a greater extent than the more primitive defenses which characterize earlier stages of 
development, e.g, projection, introjection, and denial; turning against the self, displacement (Blanck and Blanck, 1974).

Coincident with the development of defenses for adaptation is the development of cognition from the primary processes of memory traces, delay, perception, motility, intentionality, reality testing, locomotion, object comprehension, speech, to the secondary functions of concrete operational thought and abstract thought (Blanck and Blanck, 1974). Concrete operational thinking (Sarnoff, 1987) describes

a step in the improvement of reality testing which begins at $71 / 2$ years of age.... The importance of this development to the state of latency is that fantasies, which are under the impact of improved reality testing, become less useful for discharge of drives (p. 11).

Sarnoff (1987) adds that "during latency many verbal concepts are remembered in association with high charges of affect" (p. 10). Piaget and Inhelder (1969) add that "affectivity constitutes the energetics of behavior patterns whose cognitive aspect refers to the structures alone. There is no behavior pattern, however intellectual, which does not involve affective factors as motives" (p. 158).

\section{Fantasy in Latency}

Laughlin (1983) defines fantasy as "an imaginary sequence of events or mental images which seek to resolve 
emotional conflict" (p. 110). Fantasy provides imaginary gratification, substitutes for proscribed actions, permits the indulgence of unacceptable sexual or aggressive impulses, and promotes the planning of future action.

\section{Defensive and adaptive functions. Ausubel (1952)} considers fantasy a withdrawal technique, along with negativism and insulation; they "remove the self beyond the reach of threatening influences in the distasteful environment, and make it invulnerable to attack...." (p. 18). Anna Freud (1966) notes that fantasy provides the ego with "the power of surmounting considerable quantities of objective unpleasure" (p. 81), and that "the method of denial, upon which is based the fantasy of the reversal of the real facts into their opposite, is employed in situations in which it is impossible to escape some painful external impression" (p. 93).

Fantasy thus assists the latency child in adapting to a variety of situations in that "magical adjustments to problems become possible. In latency, this is necessary for the most part because of the limited physical and sexual equipment of the child" (Sarnoff, 1987, p. 229).

Sarnoff (1987) explains that the child, when confronted by situations in reality which cannot yet be mastered, uses "fantasy formation, regression, and restraint.... The goal is to master intrapsychically what is otherwise impossible to master in reality" (p. 48). 
The formation of fantasy takes the following process (Sarnoff, 1987): The child initially remembers the stressful experience, such as humiliation, physical or sexual abuse. Then, repression is used to shatter the memory and displace its fragments "onto symbolic representations that are then elaborated and synthesized into a series of coherent conscious fantasies. These fantasies discharge the drives and protect the mental equilibrium of the latency state" (p. 31 ).

Thus (Sarnoff, 1987):

the child quelis the humiliation of trauma and the excitement of drive activation through seduction by dismantling the memories of the traumatic events or seduction and the latent fantasies that they stir up.... By reliving events couched in the symbols and stories of latency play, the child is able to find an outlet for his heightened drives and yet maintain a state of latency. Thus, he gains comfort or revenge without threatening the situation in which he hopes to function well (i.e., school) or interfering with his emotional equilibrium or adjustment (p. 234).

The use of fantasy to deny "the existence of objective sources of anxiety and unpleasure (Freud, 1966) ... is wholly inconsistent with ... its capacity to recognize and critically to test the reality of objects" (p. 80). Freud (1966) adds that the developing ability to test reality reduces and then eliminates the reliance on fantasy as an adaptive defense against trauma. It loses its utility when it disturbs the capacity for reality testing. 
The structure of latency enables the child between ages $s i x$ and twelve to meet the developmental tasks of this period of maturation and development. As the child proceeds through latency, the reliance on denial in fantasy to master trauma in reality becomes less functional or adaptive as the capacity for reality testing improves. Stresses which exceed the child's capacity for reliance upon the structure of latency, particularly loss events, are the focus of the following sections.

\section{Reactions to Loss}

According to Nagera (1981), "most observations indicate that latency children deal with serious losses, through death, with massive denial, including denial of affect and not infrequently even reversal of affect" (p. 384). While mourning, the child may create

a fantasy 1 ife where the lost object may be seen as alive and at $t$ imes as ideal... not a suitable substitute for an absent parent, but it may well be an unavoidable alternative, especially if suitable substitutes are not readily available to the child (p. 385).

Also (Nagera, 1981), observation of the behavior of children suffering loss suggests little overt effects of grief, the consequences of the loss produce alterations which may affect subsequent development. Rather than mourn, children manifest disorders of behavior and other symptoms.

Wol fenstein (1969) identified adaptive substitutes for mourning. One is the provision of a substitute parent. The 
child can form an attachment to this person and simultaneously "detach" from the parent. Or, the child can use the memory of the lost parent and admiration to form the standard--"ego ideal"-- to which the child can aspire (p. 458).

Maladaptive reactions (Wolfenstein, 1969) are expressed as rage rather than as grief. The rage is directed at others in order not to lose the "representation of the lost parent" (p. 459). Bowlby (1980) adds that the experience of a "childhood bereavement" predisposes one to psychiatric disorder which includes the risk of "serious suicidal ideation, anxious dependence on another, and major depressive disorder (psychotic)" (pp. 300-301).

Bowlby (1980) also reports a study by Cain and Fast (1972) which found that in children whose parent had committed suicide a high incidence of psychopathology existed and was compounded if the children had been made to feel guilty and responsible for a parent's condition and if the reason for the parent's death was told to the child contrary to the reality known by the child. Symptoms included distrust of others and themselves, inhibited curiosity, and "a tendency to find everything unreal" (p. 388).

Even the loss of a "feeling of well-being previously experienced by the child" interferes with the child's development (Toolan, 1981, P. 316). The loss of a loved one 
(Toolan, 1962) causes the child to hate the lost object through feelings of abandonment. This includes experiences of neglect. Dependent upon the parents for love and sustenance, the child maintains the hope that the parents will supply the needed support. The defenses of repression and denial are utilized to protect against the child's comprehension of the situation, and the child begins to think of himself as bad rather than the parents. As reality testing improves with maturation, these defenses no longer suffice to protect the child. Hostility and increasing guilt replace them. While this occurs, the internalizing processes of introjection and identification operate in the process of personality formation, and "hostility previously directed towards the parents is directed towards their introjects within the child" (p. 723).

\section{Depression in Latency}

Schecter (1957) emphasizes the child's dependence on the parent, the "love object.... Thus, whenever children feel the threat of the loss of a love object, they not only develop feelings of rage toward the frustrating object, but feelings of helplessness and of worthlessness as well" (pp. 131-132). He considers this reaction a depression, or its equivalent. Sarnoff (1987) reviews "three distinct clinical entities" associated with clinical depression in latency: "emotional acrescentism (affect starvation), frank depression, and depressive equivalents" (p. 219). Affect 
starved children "tend to form quick and very close attachments with older people ... but appear incapable of remembering the good things that were done for them by the people to whom they attach themsel ves" (p. 219).

In early latency, they do not appear depressed, "but they become resentful, angry, and depressed in late latency" (Sarnoff, 1987, p. 219). These children perceive people as cruel, unreliable, and untrustworthy because of their own inability to create a "reassuring image of a new object." Their need for nurture goes unfulfilled in that they cannot establish a "relationship close enough to produce a sense of loss that would limit hostile, demanding, regressive states" (Sarnoff, 1987, p. 219). They feel betrayed and lonely, and have expectations of hopelessness. They are susceptible to depression.

The denial and fantasy of affect-starved children defend against depression until they reach the age of eleven, when their reality testing overrides fantasy. They may begin stealing and acting out with hostile aggression followed by "suicidal ideation and manifest depressive affects.... Rare is the person in this group who has depression with guilt" (Sarnoff, 1987, p. 220).

Latency age children (Sarnoff, 1987) suffering from frank depression "manifest sustained clinically depressed moods" (p. 221). Dther signs include anhedonia, dysphoria, 
and "accident proneness and direction of aggression toward the self, such as suicide attempts" (p. 221).

Depressive equivalents in latency appear to reduce and shorten "the symptomatology of clinical depression ... and the patients manifest their depressive illness in masked and cryptic forms" (Sarnoff, 1987, p. 222). Sarnoff considers the structure of latency to constitute the phenomenon which "alters the course of the symptomatology of clinical depression in the majority of patients" (p. 222). The child's defenses follow the pattern described above in order to endure or obliterate their painful affects, including depressive ones. "Therefore, even severe depressive states during latency show less depressive affect than is found in their adult equivalents" ( $p .222$ ).

Common sources of depression include anger arousing situations with no outlet for its expression and the experience of humiliation. The mechanisms of projection and actualization enable the child to master humiliation in displacement. That is, other children, onto whom displacement occurs, serve the child's purpose as play symbols. The child uses them, the actualization, in fantasies of mastery (Sarnoff, 1987).

The successful operation of these mechanisms turns hostile aggression from the child. Their failure results in observable manifestations of depression, that is, 
"aggressive energies turn inward, and depressive symptomatology is released" (Sarnoff, 1987, p. 224).

Sarnoff specifically recognizes suicidal behavior as an element of two of the three types of depression attendant to latency--affect starvation and frank depression. The manifest symptomatology of these types illustrate the tenuousness of the structure of latency in particular groups of children. Affect starved children have only partially created a latency structure and depressed children may have "lost" its protection, had they enjoyed it previously. In particular, the depression of affect starved children includes elements--object hunger, hopelessness--resulting from disturbances in early object relations development.

The predominant and manifest affect, rage, constitutes these children's reactions to object loss. Released upon the environment and/or themselves in self-destructive actions through the force of unrestrained aggression, their aggression disrupts the relative protection of the structure of 1 atency.

These children are left to rely on psychological mechanisms (ego defenses) characteristic of normal development during the separation-individuation process. For latency-age children, the defenses can be considered maladaptive, age inappropriate, or primitive. They represent children who have not acquired a structure of 
latency proper, or who have regressed from a previously establi shed structure of 1 atency. 


\section{CHAPTER IV}

\section{REVIEW OF THE LITERATURE}

Research on suicidal behavior in latency children has typically focused on their family environments, affective states, and aspects of ego functioning such as cognitive functioning (including reality testing) and cognitive development, concepts of death, fantasy, coping strategies, and ego defenses. Other research has examined suicidal children's attitudes towards 1 ife and death, and their motivations for suicide.

\section{FAMILY ENUIRONMENT OF SUICIDAL CHILDREN}

Asarnow, Carlson, and Guthrie (1987) found that "children who attempted suicide saw their families as less cohesive, higher in conflict, and less controlled than did nonsuicidal children" (p. 364). Pfeffer (1981b) identified five features of the families of suicidal children marked by their intensity and chronicity: 1. lack of generational boundaries manifest by "expressed hostility, feelings of deprivation, low self-esteem, and magnified attachment to the parents' families of origin" (p. 331); 2. severely conflicted spouse relationships including the ever-present 
threat of separation, frequent depression or suicidal tendencies; 3. parental feelings projected onto the child, both libidinal and aggressive; 4. symbiotic parent-child relationship interfering with the child's developing autonomy; 5. inflexible family system in which "change is felt as a threat to the survival of the family" (PP. 331332).

Coinciding with these five features is the "expendable child concept" (Pfeffer, 1987), a term devised by Sabbath, which postulates that parents harbor

conscious and unconscious ... wishes that a child must die. The parents view a child as expendable and a child perceives the parents as oppressors. When such a dynamic is operative, families have great difficulty in appreciating the lifethreatening state of a child (p. 181).

What Pfeffer (1982b) considers unique about the family of the suicidal child is:

the intensity and unchangeability of perceptions, fantasies, wishes, anxieties, fears, and interactions of family members. Furthermore, the similarities described for families of suicidal children and families of schizophrenic and borderline children may, in part, elucidate why there is such a high frequency of suicidal behavior among schizophrenic and borderline children (pp. 241-242).

Kosky, Silburn, and Zubrick (1986) compared 481 children with symptomatic depression with 147 children with depression and suicidal ideation. They found that the suicidal ideation group had disturbances in child-father and child-sibling relationships "characterized by persistent discord, and the child was more likely to suffer from 
persecution, hostility, and child abuse" (p. 524). Both groups had high levels of disturbance in child-mother relationships. "The vast majority of all cases recorded as positive for suicidal ideation were also positive for symptomatic depression" (p. 526). Other psychiatric diagnoses did not "show specific links with suicidal ideation" ( $p$. 527); neither did they confirm a relationship between loss and suicidal thoughts:

Whether or not children developed suicidal ideation depended significantly on the family relationships. Discordant, hostile family interactions predisposed to suicidal thoughts. Family history of psychiatric disorder or suicide was not associated with suicidal ideation in children. Extrafamilial stresses and other influences previously identified as being associated with suicidal behavior in children, such as experiences of loss, were also not found to differentiate between the two depressed groups ( $p$. 527).

These findings point toward families in which children actively involve themselves in family interactions as recipients of parental hostility and its attendant rejection.

\section{Cohen-Sandler, Berman, and King (1982) found that}

suicidal children usually remained intensely involved with family members and peers. In fact, their investment in these relationships was often expressed as rage; nearly two-thirds of suicidal children also made homicidal threats, gestures, or at tempts (p. 184).

They consider children's suicidal behavior a result of

a modeling process whereby parents, although they themselves were not suicidal, did present to the potentially suicidal child an example of interpersonal conflict, avoidance, impulsivity, and lack of more adaptive coping skills.... In a context 
of repeated losses and stressful experiences, children's self-destructive and/or homicidal behavior seem to be last ditch strategies to affect or coerce those who threaten their psychological well-being (pp. 184-185).

Friedman, Corn, Hurt, Fibel, Schulick, and Swirsky (1984) compared 16 suicidal, depressed adolescents with 18 non-suicidal, depressed ones. They interviewed the subjects using the Schedule for Affective Disorders and Schizophrenia and made diagnoses using Research Diagnostic Criteria and the DSM-III. Thirteen of the suicidal subjects and 14 of the non-suicidals were diagnosed with personality disorders. Both groups' families had no differences in psychiatric disorders, but the distinguishing factor ( $p<.02)$ separating the suicidal group was "the chronic illness of a parent during the adolescent's childhood or latency years, particularly depression," $63 \%$ compared with $22 \%$ (p. 395). Chronicity was measured at more than 24 weeks; it actually measured in years.

Pfeffer, Conte, Plutchik, and Jerret (1980) found no difference in "psychopathology, including severe depression, psychiatric hospitalization, and alcohol and drug abuse ... marital tensions, separations, parental violence, and child abuse" in the parents of outpatient children evaluated for suicidal behavior (p. 706). Parents of children considered suicidal had significantly more suicidal ideation (p. 707 ).

Parents seemed incapable of appropriately responding to their child's developmental needs because they lacked awareness and knowledge of child development, and most significantly because of serious problems 
with object relations. The parents appeared to be very dependent, lacked the ability to delay gratification, were subject to intense mood shifts, and lacked internalization of appropriate parenting qualities. They seemed not to be able to differentiate their needs from those of their children.... The suicidal children frequently blamed themselves for family problems, were unable to develop trust, and felt they were bad and in need of punishment (p. 709).

Pfeffer, Plutchik, and Mizruchi (1983) found that children they labeled "assaultive-only" and "assaultivesuicidal ... experienced significantly more parental violence than" non-assaultive, nonsuicidal children and suicidal-only children (p. 155). Parents of both groups of suicidal children "had significantly more suicidal behavior than the parents of the other children" (p. 155).

In Australia, Kosky (1983) compared 20 suicidal chldren under age 14 with 50 psychiatric controls. Sixtyfive percent of the suicidal children had witnessed physically violent arguments between parents; sixty percent had received parental abuse. Non-suicidal children rarely experienced violence.

In a study of 34 children identified as severely depressed and suicidal or self-abusive, Paulson, Stone, and Sposto (1978) cite "the identity diffusion and ego fragmentation of many suicidal families, where emotional disorganization, and severe depression are primary correlates of a markedly pathological home environment" ( $p$. 227). They found "a significant association ... between the violence in the ideational processes, the mutilating assault 
upon the body, and the extreme chaotic, disorganized state of the family" (p. 233). "Violent fighting by means of knives, razors, and guns was, for several homes, the family vehicle for expressing conflict" (p. 238).

Using a chart analysis method, Myers, Burke, and McCauley (1985) identified $17.5 \%$ of 346 inpatients aged 5 to 13 as acutely suicidal. They found that family violence, especially between biological parents, discriminated suicidal from nonsuicidal children. They found that violence distinguished depressive suicidal children from conduct disordered ones. They also identified a pattern between parental violence and suicidal behavior:

Parental suicidal behavior is related to the expression of childhood suicidal activity, although not its severity.... The underlying psychopathology may then be conceptualized as an impulse dyscontrol which predisposes aggression.... The development of self-directed violence may depend upon another $r i s k$ factor acting synergistically with this existing psychopathology, e.g., parental depression, and acute life stress. In this context childhood suicide may be viewed as a final common pathway for a heterogeneous group of children sharing a tendency toward aggression.... This child's recurrent attempts, early developmental history, and a family history of alcoholism and violence all suggest a developing character pathology, evident before puberty, despite the acute depressive symptomatology (p. 479).

Shafii, Carrigan, Whittinghill, and Derrick (1985) conducted psychological autopsies on 20 suicide victims by interviewing their families, relatives, and others such as teachers, ministers, and physicians. For controls, the researchers used victims' friends and their families $(n=17)$. 
Distinguishing significantly between suicidal victims' families and the controls were a prevalence of suicidal behavior among parents, relatives, friends, parental history of emotional problems, parental absence, and physical or emotional abuse.

Orbach, Gross, and Glaubman (1981) interviewed the families of 11 latency age children who had either threatened or attempted suicide. No control group was used. They found that "seven out of the eleven children had one parent, usually the mother, who exhibited suicidal behavior or ideation to some degree" (p. 182).

In 10 of the 11 families, a major crisis, usually centering around a handicapped sibling, required the suicidal child to relinquish needs in order to assist the family. Nine of the children felt the demands of parents exceeded their capacities, and "a refusal to comply was followed by punishment, withdrawal of love, or inducement of strong guilt feelings" (p. 183).

Findings led the authors to conclude

that suicide in youngsters is an end result of an acting out process of the family's unconscious suicidal behavior. Similarly, Ackerly (1967) posited that suicidal children identify with the suicidal parent and act out the parent's selfdestructive wishes (p. 182).

Rosenthal, Rosenthal, Doherty, and Santora (1986) compared nine, hospitalized, suicidal preschoolers, mean age four, with 16 suicidal outpatients and 16 behaviordisordered outpatients. Family psychiatric history did not 
distinguish suicidal inpatients and outpatients; it did distinguish suicidal inpatients from behavior-disordered ones. Qver half (55\%) the mothers of suicidal inpatients had been diagnosed with a depressive disorder compounded by substance abuse, and forty percent had at least one family member who had attempted suicide.

Research findings appear consistent in describing family environments of suicidal children as inimical to children's normal development. Suicidal children exist in families characterized by extreme rigidity, intense involvement combined with the threat of separation, parental use of children to gratify their emotional needs, parental depression and suicidal behavior, and parental hostility, violence, and abuse.

The expression of hostility between parents and directed toward children appears as a distinguishing factor in ten of the studies cited. Dthers include parental suicidal ideation and/or behavior, cited in four of the studies. The identification of this variable seems critical in that it appears to distinguish violent children from violent, suicidal ones.

Parental suicidal behavior and attitudes reflect "overriding egocentrism, coupled with a tendency toward intense jealousy and manipulation of love objects," which prevent a child from taking in positive attributes of the nonsuicidal parent (Hutchinson \& Dragun, 1987, p. 292). 
With the stress of parental hostility and violence, children have to adapt to chronic, stressful, chaotic environments. Doing so involves the internalization of parental behaviors, thoughts, and coping techniques. Hostile aggression dominates the internalized object-representations. The child's resulting self-image includes elements of hostility and a predisposition to violent behavior.

\section{LOSS, DEPRESSION, HOPELESSNESS}

Shaffer (1974) speculates that "changes in the phenomenology of depression which makes the child less likely to commit suicide before puberty" (p. 286) accounts for the relatively few suicides by latency children. He adds, "it may be that feelings of hopelessness which lead to the thought of suicide only become manifest at puberty" ( $p$. 286).

Shaw and Schelkun (1965) hold that "The most significant environmental factor seems to be the element of loss--a death, desertion, or separation which traumatically alters the child's environment" (p. 160).

Kosky (1983), cited above, found significant differences regarding loss experiences between the 20 suicidal children and 50 psychiatric controls. Eighty percent of the suicidal children reported loss of a parent by separation or death, twenty percent the loss of a 
grandparent or sibling or pet or possessions, thirty percent more than one 1 oss.

In a study of 102 psychiatrically referred children and adolescents, Carlson and Cantwell (1982) used the Children's Depression Inventory and a semistructured interview to identify groups of suicidal ideators and attemptors. They found that "feelings of hopelessness" failed to distinguish suicide attempters and nonattempters and children and adolescents. Attempters measured only slightly more depressed than nonattempters (p. 365). They made a clinical finding "that the rate of reported depressive phenomenology increases across increasingly suicidal youngsters and that the number of subjects with fanily members reporting no psychiatric disorder decreases" (p. 366). They conclude

that the relationship of suicidal ideation, depression, and depressive disorder is clearer than that between suicide attempt and depression. Suicidal ideation is perhaps a barometer of the severity of depression in many young people regardless of age (p. 367).

Cohen-Sandler, Berman, and King (1982) reviewed the medical records of 76 children as they were discharged from a psychiatric hospital. Two trained raters, who did not know the experimental hypotheses, assigned each child to a suicidal group, a depressed, nonsuicidal group, or a control group. Assignment to the suicidal group required suicidal behavior or verbalizations. Twenty (26\%) of the children were considered suicidal, 21 depressed, and 35 controls. 
Seventy percent of the suicidals had received borderline personality diagnoses in their discharge diagnoses, compared with $33 \%$ of the depressed and $29 \%$ of the controls. Depression was diagnosed in $65 \%$ of the suicidal children, but suicidal behavior occurred in only $38 \%$ of depressed children.

The suicidal children, compared with depressed and control groups, experienced more frequent losses of parents and grandparents the year prior to hospital admission.

Of the 100 symptoms evaluated, two, "depressed affect and threatening people.... specifically characterized the suicidal group" (Cohen-Sandler et al., 1982, p. 185). Fifty percent of the suicidals expressed threats compared with $10 \%$ of the depressed and $11 \%$ of controls. Considering the stressful life events and numerous losses of the suicidal children, the authors consider the distinguishing symptoms "internalized and outwardly expressed rage" reactions to their situations (1982, P. 185).

Kazdin, French, Unis, Esveldt-Dawson, and Sherick (1983):

examined if hopelessness discriminated between suicidal and nonsuicidal patients and if hopelessness, depression, and suicidal intent were interrelated among children in the way they have been among adults (p. 504).

Depression measures assessed current symptomatology; hopelessness assessed future expectation. They found 
suicidal intent "more clearly related to the degree of hopelessness than to severity of depression" (p. 508):

The relationship between suicidal intent and depression was not significant when hopelessness was controlled statistically. In contrast, the relationship between suicidal intent and hopelessness remained relatively constant whether or not severity of depression was controlled.... (Children) who attempted suicide were not significantly different in their hopelessness from those who threatened or repeatedly thought about suicide. Thus, hopelessness may predict children's thoughts about suicide, but other variables apparently dictate whether an actual attempt is made. Nevertheless, hopelessness may still be clinically useful as one risk factor for suicidal intent ( $p$. Sog).

Garfinkel, Froese, and Hood (1982), by reviewing emergency hospital admissions of children and adolescents over a seven-year period, found the 505 suicidal children exhibited significantly more dysphoric affect, hostility and aggressiveness, and stronger reaction to crisis than did the same number of controls.

In a study of suicidal behavior in 101 "randomly selected preadolescent school children," Pfeffer, Zuckerman, Plutchik, and Mizruchi (1984, p. 416) identified 12 considered suicidal, 9 because of ideation, 3 because of threats or attempts. Factors associated with these 12 children included recent depression and depression in the child's history, but no major depression. Recent and past depression also correlated significantly with suicidal behavior in child psychiatric inpatients and outpatients Pfeffer, Plutchik, Mizruchi, and Lipkins (1986). 
Orvaschel, Walsh-Allis, and Ye (1988) formed two groups of children, high-risk and low-risk. The high-risk group consisted of 61 children from 34 families in which a parent had experienced at least three episodes of major depressive disorder. The low-risk group consisted of 45 children from 29 families from a community; neither parent met DSM-III criteria for any Axis I psychiatric disorder. "Forty-one percent of high-risk children met criteria for at least one psychiatric disorder, at some time in their lives, compared with $15.2 \%$ of low-risk children... the high-risk group more frequently met criteria for multiple diagnoses" (p. 21). Of import, "all the females had a prepubertal onset of affective illness, as did all but one of the males" (p. 23).

The findings of Cohen-Sandler et al. (1982) and Kosky (1983) appear to demonstrate an inordinate number and frequency of loss events experienced by suicidal children. Findings regarding depression and suicidal behavior show relationships between severity of depression and suicidal behavior. That is, the more severe a child's depression, the more lethal attempt the child will make. Findings also suggest that the relationship between depression and suicide is neither a necessary nor a sufficient predictor of suicidal behavior. That is, not all seriously depressed children attempt suicide, nor are all suicidal children depressed, at least according to the measures used. 
The relationships among hopelessness, depression, and suicide also appear mixed. Carlson and Cantwell's (1982) study found that hopelessness failed to discriminate between attemptors and nonattemptors as well as between children and adolescents. This finding disputes Shaffer's comment regarding a change in children's hopelessness and depression at puberty. Kazdin et al. (1983) found hopelessness had a greater relationship with suicidal behavior than did depression although they consider that other variables must operate in order for suicidal behavior to occur. Suicidal ideation constitutes one of the other variables and will be addressed in subsequent sections.

Depressed affect and hostility expressed toward others in the form of threats appeared as discriminating variables in two studies, Garfinkel et al. (1982) and Cohen-Sandler et al. (1982) and in the latter as the only two distinguishing symptoms. Cohen-Sandler et al. (1982) interpret these variables as rage expressed inwardly and outwardly as "lastditch strategies to affect or coerce those who threaten their psychological well-being" (p. 185). Because those who threaten children's well-being are primarily their parents, and because suicidal children appear involved in chaotic, hostile, violent families, their mistreatment and its effects may constitute a eritical variable in their suicidal behavior. 
Feelings of hopelessness, or more accurately, an attitude of hopelessness (K. Smith, personal communication, March 20, 1987) may contribute to the dangerousness of a suicide attempt in a depressed, angry child for whom the future appears futile. Two studies (Kosky, 1983, Kazdin et al., 1983), and one report, (Shaw \& Schelkun, 1965), identify a relationship between hopelessness and suicidal behavior, although one (Carlson \& Cantwell, 1982), did not.

\section{COGNITIVE FUNCTIONING}

\section{Loncepts of Death}

Orbach, Rosenheim, and Hary (1987), used their Suicidal Tendencies Test with three groups of children-suicidal $(n=27)$, chronically ill $(n=25)$, normal $(n=$ 23)--aged six to twelve. The test consists of four stories about an animal who is changed into an inaminate object, or an object into an animal. The stories elicit attitudes about the attraction to 1 ife and death or repulsion to 1 ife and death. Children retell the stories, state their meanings, and explain their responses. On the attraction to death story, the examiner, a psychologist trained in administration but without knowledge of the specifics of the attitudes measured, first told the respondents that other children responded differently and asked the child to state why another child might answer differently. This 
requirement constituted the "measure of flexibility for alternative ideas" (p. 182).

Results showed the suicidal children "unable to produce alternative attitudes toward 1 i fe and death compared with normal or chronically ill children" (p. 184). The suicidal children who did demonstrate the ability to produce alternatives also displayed, unlike the other two groups, a significant relationship between alternatives and their attraction to death (p. 184). This "cognitive inflexibility" limits "the child's scope of possible solutions or coping techniques ... and suicidal behavior prevails" (pp. 181, 184).

Drbach and Glaubman (1979b) conclude from three case studies of suicidal children that their behavior

seemed to be related to distorted, idiosyncratic death concepts. Death was perceived by the children as a potentially need-fulfilling phenomenon and not merely as an escape from suffering and pain. These idiosyncratic ideations alone did not cause suicidal behavior, but were instrumental in the actualization of surh behavior in the three children (p. 676).

They consider these distorted concepts not "a massive regression in ego functioning and a rupture in total ego integrity" because the children "did not indicate such a regression in ego functioning and behavior" (p. 676). They conclude that the distortions

are a result of a defensive process. A child who contemplates suicide must either accept the terror of the finality of death or accept life with its anguish unless he is in a state of mind that facilitates self-destruction.... Another hypothesis is that the distortions reflect a misinterpretation 
of facts or indirect experience with death due to the immaturity of cognition in the early developmental stages (p. 676).

They comment that "Many children show a split in the death concept; they may have a mature concept of impersonal death, but a rather childish concept of their own personal death" (p. 677).

Drbach and Glaubman (1978) hypothesized that

an idiosyncratically distorted view of death held by children with pathology or under severe stress that elicits self-destructive behavior ... could facilitate suicidal behavior.... (because)... the threat inherent in suicidal thinking engages defenses that result in the distortion of the meaning of death. The emotional pressure experienced by the young suicidal child could affect his rather fluid cognitive structure in the direction of wishful thinking (pp. 850-851).

They also suggested an alternative: "Idiosyncratically distorted beliefs about death held by suicidal or other children could reflect a misinterpretation of facts or indirect experiences with death due to the children's level of cognitive development" (p. 851). If the latter hypothesis held, they predicted that different types of children would hold distorted views.

They formed three groups of children--suicidal, aggressive, and normal--to investigate these hypotheses. Asked what causes death, aggressive children gave significantly more responses with aggression and brutality, suicidal ones significantly more responses with suicide and self-destruction, and normal children named old age and illness. Regarding personal death, suicidal children 
"attributed life qualities to the state of death significantly more than aggressive or normal children" ( $p$. 854), but not for impersonal death. Suicidal children indicated significantly more than the others a belief of returning to 1 ife after a personal death.

The authors infer

that the child's concept of death is an integral part of his entire personality and reflects his life experience and internal dynamics. In this context, the idiosyncratically distorted death concept of the suicidal child can be interpreted best as a reflection of a defense process. Choosing suicide as a prospective solution for a troubled life is harmonious with the belief that death is another form of 1 ife or with the belief of returning to life after death. Apparently, the suicidal child protects himself against the threat of personal death by distortions and idiosyncracy (p. 855).

Orbach and Glaubman (1979a) tested the contention

that a distorted death concept at a very young age reflects a defensive process against the overwhelming fear of death. Thus, the young child describes death as reversible and temporary in order to master the realization of death ( $p .671$ ).

They compared three groups of children--suicidal, aggressive, normal--aged 10 to 12 , on measures of abstract thought (Similarities subtest of the WISC), the authors' construct of $1 \mathrm{ife}$, and their construct of death. They found that

suicidal children distorted the death concept more frequently than the other two groups, although they did not differ from those groups in other measures. Thus, the distortions in the death concept seem to be independent of general cognitive functioning. Apparently, the threat inherent in thinking about death affects the child's rather fluid cognitive structure in the direction of distortion and wishful thinking about death. Such a defensive perception 
may then serve as a new motivating force for suicide (p. 673).

Orbach, Gross, and Glaubman (1981) interviewed 11 suicidal children whose fantasies and perceptions demonstrated four common characteristics: 1. Death involves a continuation of 1 ife, but more satisfying; 2 . Deprivation of needs predominate their feelings, especially relationship needs; 3. Two views of death may coexist, one as attractive and unrealistic, the other as realistic accompanied by anxiety; 4. Personalities and mental states determine perceptions of death and fantasies.

Orbach, Feshbach, Carlson, Glaubman, and Gross (1983) consider suicide in children as

not merely a reaction to a specific problem but requires a particular state of mind and personality organization. Each of the conflicting forces can be described as a complex attitude composed of a cluster of cognitive conceptualizations, emotional states, and motivational tendencies concerning life and death (pp. 661-662).

From their study comparing 58 normal and 52 suicidal latency-age children, they conclude that suicidal children's "misconception about death (i.e., death as another form of life) is a defensive maneuver to cope with the anxiety of planning suicide rather than a reflection of cognitive immaturity" (p. 669). The attraction to death "attitude is uristable and is most sensitive to changes in suicidal behavior and to changes in life Eircumstances" (p. 669), and "along with the experience of strong repulsion by 1 ife the suicidal child shows a considerable degree of attraction to 
1 ife, which can be expressed in an obvious behavioral form" (p. 669).

In a replication study COrbach, Feshbach, Carlson, \& Ellenberg, 1984) which included terminally ill children between 6 and $12(n=28)$, the authors tentatively conclude that suicidal children's "attraction to death is a defensive maneuver of coping with death, highly responsive to changes in the child's state of mind and sense of well-being" ( $p$. 1026).

Suicidal and chronically ill children, in spite of their suffering, do not lose their attraction to life. Their feelings about life are highly conflictual, yet they are able to experience en joyment and satisfaction (p. 1026).

Pfeffer, Conte, Plutchik, and Jerrett (1980) found 13 outpatient suicidal children significantly more preoccupied with death than 26 nonsuicidal children, but found no differences in their understanding of death. The suicidal children thought of death as "a means of eliminating stress and attaining peace" (p. 710 ).

Carlson, Asarnow, and Orbach (1987) "assessed the understanding of death and knowledge of suicide" in 26 normal school children ages 8 to 13,28 inpatient children ages 8 to 10,32 inpatient children ages 11 to 13 , and inpatient young adolescents (p. 186). Among all subjects, 75\% comprehended the irreversibility of death, regardless of grade level, age, or sex; the percentage reached 100 among adolescents. Reasons given for suicide included having a 
hard time, perceiving life as terrible, hating oneself, feeling depressed, angry, hopeless, angry, useless and, among $20 \%$ of the hospitalized children, feeling crazy. School children specifically mentioned types of separations such as parental neglect, divorce, breakup, or death. The majority of all subjects answered affirmatively when asked whether one attempting to commit suicide would want to be saved.

Asked to name ways to commit suicide, younger children usually responded with shooting, stabbing, or don't know. Younger children's notions were less informed, e.g., "'bang my head against concrete until my brains fall out," "'choke myself with my hands" (p. 189). The authors consider that

age and cognitive ability does have a strong influence on imagining a lethal plan.... Taken with the fact that children are much less likely to implement what they fantasize leads to two possible explanations. The first is that preadolescent children rarely totaliy comprehend selfdestruction. They simply apply what they know about violent death, probably from the media, where shooting and stabbings are rife, to themselves ( $p$. 191).

The second explanation is that, although younger children know how to kill themselves, they are simply not invested in really doing so. In contrast with older children and adolescents, they cannot conceive of circumstances in which someone might commit suicide, and when they do their reasons are often capricious. By adolescence, and possibly with the more abstract thinking that goes with it, the emotions of self-hate, despair, and anger are recognized as motivating forces behind selfdestruction. It would appear that the frequency and possibly the intensity of these feelings increases with age as well. There may also be a greater connection with experiencing these feelings and suicidal behavior. Finally, our data indicate that maturity brings more consistency between thought and 
action. The fact that adolescents think that overdosing will kill them, ideate it, and try it suggests a greater follow-through and commitment on their part (p. 192).

Pfeffer (1985) conducted a study of 101 normal children ages 6 to 12 in a regular school setting. Twelve (11.9\%) of the students expressed suicidal actions or ideas. Compared with the remainder of the sample, suicidal children expressed significantly more preoccupation with death, "more recent and past depression, more suicidal thoughts among the mothers, and a greater tendency ... to use introjection as an ego defense" (p. 79). The children worried about their families, knew their mothers were depressed, and had "definite concepts about death and conscious intentions to kill or severely injure themselves" (p. 80) and their ideation included highly lethal methods: stabbing, hanging, drowning, jumping from high places.

Pfeffer's study (1985) reveals that suicidal children speak openly and with clarity about death and their conscious intentions of self-destructive actions. They also (Pfeffer, 1981a) "have distinct concepts that death is reversible and that death provides a temporary state of pleasantness... unconsciously equated death with gratification of wishes from an all-giving and passive mother" (p. 116).

For comparison, in a study of non-suicidal children, Koocher (1973) used Piaget's framework of cognitive development (i.e., preoperational and concrete operational 
subperiods, formal operational period) in his study of 75 children of at least normal intelligence aged six to fifteen to ascertain their thinking towards death. Eight children, all preoperational (40\% of the category), considered death reversible; no children in the other groups believed death reversible. Preoperational thinking persisted through age 9-10 in boys $(n=2)$ and $8-9(n=1)$ in girls although one girl, 10-11, was rated preoperational.

With younger children, Rosenthal et al. (1986) formed four groups based on suicidal fantasies and behaviors: The "self-punishment" group had suffered parental physical abuse "and came to regard themselves with the same hostility and criticism that others had expressed to them"; these 6 boys viewed death as irreversible (p. 207). The "reunion with a central nurturant figure" category, 1 boy, fantasied a wish to "rejoin a loved one" and viewed death as reversible (p. 208). The "escape and rectification of an unbearable life situation" category, 1 girl, expressed wish fulfillment "dictated by instinctual forces" (p. 209). The "selfpunishment and reunion" category (escape) results from a fantasy for rescue from an intolerable life situation in which the child can think of no alternative (p. 210).

Most children, including some pre-operational ones, comprehend the irreversibility of death. Considerations of suicide require a means to overcome the fear of annihilation; a belief in the reversibility of death 
provides the means for some children, in spite of their comprehension of the irreversibility of impersonal death.

Orbach et al. (1978, 1979a, 1979b, 1981, 1983, 1984) consider suicidal children's belief in the reversibility of death to constitute part of a defensive process which allows suicidal action to occur. The defensive process involves a cognitive distortion in the comprehension of the finality of personal death. Pfeffer's (1981a) study appears to support these conclusions, for the children believed that death would provide gratification. Pfeffer's (1985) study of schoolchildren suggests that those considered suicidal saw death as final. The Orbach studies particularly show that the defensive process which allows suicidal behavior to occur may alleviate the anxiety of planning and executing a suicide; yet, it seems that it constitutes the failure of defense mechanisms in that it fails to protect from suicidal behavior.

\section{Suicidal Fantasies}

Pfeffer (1986) defines suicidal fantasies "as special ideas that provide the reason for suicidal actions. These fantasies are consciously expressed ideas that have unconscious derivatives" (p. 162). She identifies wish fulfillment and the diminution of painful states as fantasies which may impel suicidal action when they fail to bring about their intended purpose. Component motives (Pfeffer, 1986) of suicidal fantasies include the wish to 
kill and to dief a wish for rescue, to escape unbearable circumstances, to achieve a pleasant state, to punish parents, to reunite with kind parents.

Gould (1965) adds the motives of the wish to "gain support and strength through joining the power ful lost loved object," to retaliate for abandonment or its threat, to manipulate in order "to obtain love and attention," to atone for sins, and to murder oneself (p. 237).

In a survey of 652 children (including adolescents) and their mothers, Velez and Cohen (1988) found greater frequency of suicidal ideation in children's reports than in the mothers" reports of their children.

Reporting on the attempted suicide of a 7-year-old boy, Friedman and Corn (1985) reveal the boy's fantasies as his death would cause his parents to reunite, revenge against parents, and "the need to obtain control and repair his self-image by identification with superman.... Paradoxically, even as he wished to die, he wished to be an invulnerable superhero" (p. 111).

Santostefano, Rieder, and Berk (1984), on the assumption that "movenent in Rorschach imagery has long been viewed as indicating one's capacity to reflect and rehearse one's actions in thought" (p. 4), posed two hypotheses: that "fantasy mediates between impulses and actions by interpolating delay and serves as a way of rehearsing action in thought before these actions are performed in reality" 
(p. 3) and that suicidal behavior represents "a form of maladaptive action" (p. 4). They administered the Rorschach Test to 32 children between 8 and 16 hospitalized for suicidal behavior, to 91 children hospitalized for other psychiatric disorders, and to 44 school children. Suicidal children under $121 / 2$ imagined more completed motion, acted as agents of motion rather than imagining agents, constructed fantasies of motion closely connected with reality, and imagined more vigorous motion. This finding suggests that suicidal children's fantasies are tentative, that they failed in their functions of gratification and discharge.

Carlson et al. (1987) compared suicidal children's concepts of which suicidal actions would prove fatal with those they fantasized for themselves and with the methods used in their attempts. Hal $f$ of the children

thought about killing themselves in ways that corresponded to their general knowledge about methods; $20.7 \%$ of children and $46.6 \%$ of adolescents made suicide attempts that corresponded with their knowledge.... whereas only $20.7 \%$ of children implemented their fantasies and did what they ideated, $100 \%$ of adolescents made attempts that corresponded to their fantasies $(p=0.03$ ) ( $p .190)$.

Pfeffer (1982a) compared three hospitalized suicidal children aged 6 to 12 diagnosed as neurotic, borderline, and psychotic to help determine

whether fantasies or wishes that promote suicidal symptom formation are different in children with varying degrees of psychopathology .... (and)... whether ego functioning that is associated with the expression of suicidal behavior 
differs in children with varying degrees of psychopatholagy (p. 121).

The neurotic child"s fantasy "represented a wish to control the parents and get them to be more concerned about her needs and feelings," the borderline child's to "control her frustrating mother, to rectify the perceived family injustices, and to gain support from her parent," the psychotic child's to relieve and control intense confusional turmoil with the help of a powerful omnipotent parent" (p. 129). Pfeffer considers the suicidal fantasies similar and as expressions of "wishes of having powerful, all gratifying parents who could decrease frustration and withstand the children's aggressive and libidinal impulses" (P. 129).

Children's reliance on fantasy gratification to sustain themselves seems to include an inherent risk that the same reliance over time allows a shift in fantasy as protection to one as preparation for action. That is, if fantasy cannot provide relief its adaptive, defensive function fails to protect the child from self-destructive actions and even provides the means to planning suicidal actions.

PSYCHOLOGICAL MECHANISMS

\section{Coping Strateqies}

Cohen-Sandler, Berman, and King (1982) identified a suicidal grouping of 20 children in a study of 76 subjects ages 5 to 14.. Fourteen of these children had received a 
border 1 ine personality diagnosis; 13 were depressed. The authors conceptualize the suicide attempts as "active coping efforts to counteract the sense of helplessness they felt in being unable to effect changes in the stressful, chaotic conditions of their families" (p. 184). The active coping efforts took aggressive forms, half the suicidal group threatening people compared with 10\% of depressed children and $11 \%$ of psychiatric controls. Along with depressed affect, aggression constituted the significant symptom discriminating suicidal children. The authors consider "that both internalized and outwardly expressed rage may result from these children's continuous and increasing experience with loss and 1 ife stress" (p. 185).

Asarnow, Carlson, and Guthrie (1987) "evaluated the relations between depression, suicidal behavior, and children's strategies for coping with major life stresses" (p. 362) in psychiatric inpatients ages 8-13. No significant relations emerged between "degree of suicidal behavior and perceived competence measures," between hopelessness and suicidal behavior when controlling for depression, or between hopelessness and perceived competence when controlling for depression (p. 364).

Children with suicidal ideation showed less 1 ikel ihood to generate active cognitive coping strategies. Hopelessness was associated with severity of depression and increased suicidal behavior. Depressed and nondepressed 
children scored similarly on achievement and IQ tests; thus, "negative self-perceptions of depressed children represent negative biases rather than true differences in competence" (p. 364). "The quantity of adaptive coping strategies that children generated ... did not differentiate diagnostic groups of suicidal and nonsuicidal children" (p. 365), but "nonsuicidal children generated more active cognitive coping strategies than suicidal children" (p. 365). The authors consider this finding as suggesting "that suicidal children may fail to spontaneously generate cognitive mediational strategies to regulate their affective and behavioral responses to stressful life events" ( $p$. 365).

Carlson and Cantwell (1982)

hypothesized that children with more chronic problems would feel more desperate and have fewer coping skills ... (but) ... it did not appear that duration of psychopathology as we defined it played a part in suicidal behavior (p. 365).

Orbach et al. (1981) discovered that the "majority" of

11 suicidal children interviewed

revealed, alongside the problematic aspects of behavior, healthy personality characteristics and a strong will to stay alive. They tried to form interpersonal relationships, expressed their creativity, and showed altruism as well as sensitivity to others (p. 186).

The authors interpret their findings as

representing a healthy and positive motivation to cling to life. In addition, contradictory to what has been stated by Ackerly (1967), suicidal behavior is not necessarily an expression of total regression and development or of a process of mental deterioration. This phenomenon explains the frequent surprise that people show when they are 
faced with suicidal behavior among young children. The positive and healthy aspects of behavior can mask the inner turmoil and depression (pp. 186-187).

Suicidal children's difficulty devising adaptive coping strategies seems expected considering suicidal children's cognitive rigidity, the effects of depressive symptoms on cognitive functioning, hopelessness, and rage. Given their parental modeling, active coping strategies devised spontaneously by suicidal children appear rigid and few. Suicidal behavior thus constitutes a very $r i s k y$ and desperate attempt to effect change in their lives.

\section{Eqo Defenses}

Pfeffer, Conte, Plutchik, and Jerrett (1979) identified 42 children as suicidal from an inpatient population of 58 children ages 6 to 12 . To discriminate these children, they had devised "eight structured Child Suicide Potential Scales" from clinical experience and a literature review to identify "variables most likely to be relevant to suicidal behavior in children" (p. 681). The scales are Spectrum of Suicidal Behavior (a five-point scale), Precipitating Events, Affects and Behavior--recent, Affects and Behavior--past, Family Background, Concept of Death, Ego Functioning, and Ego Defense Mechanisms. Each child's therapist, a child psychologist or child psychiatrist, administered the battery; the standard clinical evaluation included the WISC-R, Forschach, Thematic Apperception Test, Bender-Gestalt test, and Human Figure 
Drawings. After administering the battery, the therapist wrote a detailed report. Thirty of the reports were selected at $r$ andom and read by another clinician who stated an estimate of suicidal potential on the spectrum of suicidal behavior scale without knowledge of the initial rating. Interrater reliability was +.94 on this scale. Reliability coeffecients for the other scales included affects and behavior--past, +. 98 and recent, +.82; concept of death, +.86, family background, +.71; and precipitating events, + .57. Ego functioning and ego defense scales have no reported reliability coeffecients. No validity coeffecients are stated for any of the scales.

Defense profiles for both suicidal and nonsuicidal children were similar. Commonly used defenses included the following: denial ("avoiding awareness of some painful external reality ...(by)... withholding conscious understanding of the meaning and implications of what is perceived" [Horowitz, 1988, p. 191]); projection; introjection; repression; and displacement (transferring avoided ideas and feelings "to some other person, situation, or object" [Horowitz, 1988, p. 192]). Infrequently used defenses included intellectualization cavoiding "the emotional implications of a topic by dealing with it on a purely ideational level" [Horowitz, 1988, P. 193]); undoing; and reaction formation. 
Suicidal children showed more preoccupation with death; preoccupation correlated with degree of dangerousness. They worried about family members dying; they showed more distress at the death of important persons; they conceived of death as temporary. Those who considered death pleasant showed more dangerousness.

Pfeffer, Conte, Plutchik, and Jerrett (1980) applied the same (1979) battery of suicide potential scales to an outpatient population of 39 children ages 6 to 12 years. They found no differences in defense profiles between suicidal and nonsuicidal children:

The most frequent defense mechanisms utilized were denial, projection, introjection, and repression. When intensely stressed by intrapsychic and external pressures, the defenses were not adequate to prevent symptom development, including acting out of suicidal impulses. Undoing, reaction formation, and intellectualization were the least frequent defense mechanisms (p. 708).

Specific risk factors include the "wish to die, intense preoccupations with death, and suicidal behavior in the parents" (p. 708).

The suicide potential scales were employed in a study of 102 inpatients ages 6 to 12 years (Pfeffer, Plutchik, and Mizruchi, 1983). Each interview of children and parents was observed by "two experienced interviewers simultaneously" who independently completed the scales (p. 154). Interrater agreement on all the scales was high, $92 \%$ to $100 \%$, and internal reliabilities were significant. 
Pfeffer et al. labeled 17 of the subjects nonassaultive-nonsuicidal, 26 assaultive only, 11 suicidal only, and 48 assaultive-suicidal. Psychiatric diagnoses assessed 5 of the suicidal-only group with affective disorder, 12 assaultive-only children with specific developmental disorder, and 26 assaultive-suicidal children with borderline personality disorder. On measures of ego defenses, two measured significantly different: The nonassaultive-nonsuicidal group scored higher on intellectualization, the assaultive-suicidal group highest on compensation cunconscious attempt "to offset, to make up for," actual or imagined deficiencies [Laughlin, 1983, p. 183). A nonsignificant finding showed the suicidal-only group highest on reality testing. The researchers concluded that the suicidal-only children have "relatively stable ego functioning, including good reality testing, who decompensate and become overtly depressed only under the influence of extreme environmental stressors" (p. 156). Assaultive-suicidal children "have distinct ego deficits and are prone to identify with parental acting-out of suicidal tendencies" (p. 156).

Pfeffer, Zuckerman, Plutchik, and Mizruchi (1984) compared 101 normal school children "selected by stratified random sampling from a computerized roster.... to match the comparable age, sex, and racial/ethnic distributions" of 65 child psychiatric inpatients in a voluntary unit (p. 417). 
The suicide potential scales were administered to the subjects. Two clinicians observed 22 of the interviews and independently completed the scales and made DSM-III diagnoses. Inter judge reliability coeffecients for Ego Defense Scales include intellectualization $r=.96$, regression $r=.87$, undoing $r=.85$, reaction formation $r=$ 82, compensaion $r=.74$, denial $r=.72$, repression $r=$ .72, projection $r=.69$, introjection $r=.57$, sublimation $r$ $=.57$, and displacement $r=.52$.

Twelve percent of the school children had suicidal ideas, threats, or attempts compared with $79 \%$ of the inpatients. The 12 school children who manifested suicidal behavior, compared with the other school children, scored significantly higher on the variables of preoccupation with death, recent depression, Bender-Gestalt score, recent and past signs of general psychopathology, tendency of the mother to have suicidal thoughts, and the use of introjection as a defense. "Estimates of IQ, reading, spelling, and arithmetic achievement, degree of reality testing and impulse control were not significantly different for the suicidal and nonsuicidal school children" (p. 420 ).

They comment:

Compared with inpatients, the school children had higher mean scores ... on such variables as death preoccupations, sublimation as a defense mechanism, parental reports of depression, and alcoholism. The school children had lower mean scores ... on such variables as recent and past aggression, recent and past antisocial behavior, recent depression, total ego defenses, and parental separation (p. 421). 
Suicidal children in both populations scored higher than nonsuicidal children in both populations on depression, preoccupation with death, parental suicidal behavior, and introjection as a defense mechanism.

The school children (Pfeffer, 1985) adapted to parental depression by identifying with the depressed parent, withdrawing from social activities, and inhibiting their expression of aggression because they feared a parent may die. There existed no significant relationship between the presence of any psychiatric diagnosis and suicidal behavior, a finding considered tentative because of the small number of suicidal children.

Pfeffer, Plutchik, Mizruchi, and Lipkins (1986) used the same research instruments and similar methodology as cited above in a comparative study of 106 inpatients aged 6 to 12 years with 101 outpatients and 101 nonpatient school children. They found the defense of introjection a risk factor with inpatients and suicidal nonpatients. Factors associated with suicidal behavior in all three groups were recent general psychopathology, preoccupation with death, recent and past depression.

A follow-up study took place two years later (Pfeffer, Lipkins, Plutchik, \& Mizruchi, 1988) with 75 of the original nonpatient (schoolchildren) subjects, 67 of whom answered questions about suicidal thoughts or behavior; 8 children refused to answer questions about suicide. Showing evidence 
of suicidal thoughts or acts placed subjects in the suicidal category. Using DSM-III criteria, evaluators diagnosed $57 \%$ of the students with 9 Axis I and 3 Axis II diagnoses. No significant relationship existed between "a particular follow-up diagnosis and suicidal behavior," a finding similar to that in the initial study (p. 36). Grouped according to the existence of any type of psychiatric diagnosis "at the time of follow-up ... significantly more suicidal children had a current DSM-III diagnosis than the nonsuicidal children"(p. 36).

Suicidal children scored significantly higher than nonsuicidal ones on variables of depression, death preoccupations, aggression, general psychopathology, and the ego defenses of denial, reaction formation, and projection. No significant differences existed on variables of achievement in reading, spelling, arithmetic; impulse control, hopelessness; reality testing; assaultive behavior; Achenbach Child Behavior Checklist scores (all within normal ranges); ordinal position in the family; parental separation; birth weight or complications; or history of parental physical illness or psychiatric disorders. A third of all the children interviewed experienced parents" separation or divorce; "7.4\% had at least one parent with symptoms of depression, $4.7 \%$ had at least one parent who abused alcohol and/or drugs, 6.7\% had other relatives who 
attempted suicide, and $8.0 \%$ had relatives who committed suicide" (p. 38).

About $85 \%$ of the children had no suicidal tendencies at the initial evaluation or at the two-year follow-up. "Fifty percent of the children who initially reported suicidal tendencies also reported them at follow-up. In addition, 15.3\% of the children reported suicidal tendencies at follow-up but not at the initial assessment" (p. 38). What distinguished this group with statistical significance were four variables: assaultive behavior, general psychopathology, depression, and death preoccupations. The number of suicidal children at the initial study and at foilow-up, and who were suicidal initially but not at follow-up were too few (4) to derive statistical comparisons.

About 18\% (13) of the children reported ideation and 1.5\% reported threats, but no one had actually made a suicide attempt. Among those who reported ideation or threats, "most $(69.2 \%)$ were vague about having a plan for suicidal action," mentioning shooting, wrist cutting, stabbing, and jumping (p. 36). Of the 149 parents interviewed, 10\% "expressed suicidal ideas and/or acts," but no significant relationship existed between the children's or mothers' suicidal tendencies (p. 36).

The authors comment that their findings "suggest that at a given time, a prevalence of suicidal ideas for normal 
preadolescents of between $8.9 \%$ and $17.9 \%$ can be expected" (p. 39), and that

it appears that suicidal ideas may be approximately 10 times more prevalent than suicidal acts among these preadolescents, and that many factors must operate in order to influence a child to move from having a suicidal idea to carrying out a sulcidal act. These risk factors are depression, death preociupations, and general psychopathology (p. 40).

Carlson et al. (1987) identified $15.4 \%$ of normal school children as having suicidal thoughts even though their study design attempted to exclude school children who had ever received psychological services; all of these children were over age 11 .

Pfeffer (1982a) concludes that

borderline and psychotic children have characteristic defects in ego functioning which make these children more vulnerable to the onslaught of external and internal stresses. The lack of a complexly ordered hierarchy of ego defenses in borderline and psychotic children may account for the astounding incidence of such acting out behaviors as suicidal tendencies noted in these children (p. 133).

Paulson, Stone, and Sposto (1978) identified

internalized hate and anger, conscious and/or unconscious death wishes, masochistic, selfdestructive acts of violence... so intertwined with feelings of guilt and blame, that atonement and relief were possible only by escape into a suicidal state of separation from family relationships (p. 237).

In their literature review, Joffe and offord (1983)

found that

the precipitating stress preceding suicidal behaviour is only the final factor in a history of long-standing difficulties and progressive emotional decompensation; there appears (sic) to be few, if 
any, isolated, impulsive suicidal acts in welladjusted children (p. EO).

Although this section emphasized ego defensive functioning, a number of risk variables reoccurred throughout the studies: preoccupation with death (1979, 1980, 1984, 1986, 1988), parental suicidal behavior (1980, 1984), recent and past depression (1984, 1986), and past signs of psychopathology (1984, 1986, 1988). Grouped with the variables depressed affect and threatening people (Cohen-Sandler et al., 1982), the cluster seems a valid and reliable measure of risk.

A component of Pfeffer's investigations constitute attempts to isolate discrete ego defenses and their operation in suicidal children. Problems attend these efforts. They include defining the defenses as operaticanal constructs which can be observed and measured. None of the reports states how this was accomplished except for references to the source of the definitions of defenses employed (e.g., Freud, 1966). Pfeffer's book (1986) lists the defenses of the ego defense scale in terms of observable behavior, but no article contains the lists.

Whether the operation of defenses can discriminate among suicidal and non-suicidal children regardless of patient status seems essential to questions of their utility as estimators of risk. Pfeffer et al's. six studies address this question. The study (1979) of inpatient children found no differences in defense profiles between suicidal and non- 
suicidal children. The study (1980) of outpatient children also showed no differences. The study (1983) of 102 inpatients identified two significant differences, the nonassaultive, nonsuicidal group highest on intellectualization, the assaultive-suicidal group highest on compensation.

The study (1984) of schoolchildren and inpatients identified introjection as the one defense distinguishing suicidal from nonsuicidal children regardless of patient status. A comparison (1986) of schoolchildren with inpatients and outpatients identified introjection discriminating suicidal inpatients and schoolchildren. The follow-up study (1988) of schoolchildren identified suicidals with significantly higher scores on denial, reaction formation, and projection.

overall, the significant occurrence of primitive defenses--introjection, projection, denial, compensation, displacement--was twelve times for suicidal children; significance for advanced defenses--repression, reaction formation--was three times for suicidal children regardless of status. These mixed results show that raters can identify the operation of ego defenses in clinical interviews, but the utility of doing so seems only supplemental to other information sought.

Another concern involves the use of ego defenses as specific risk factors in assessing suicide potential. As 
Cohen-Sandler et al. (1982) state, "Symptomatology, in general, seems less useful than do stress and life history data for discriminating the suicidal child" (p. 185). One can readily observe assaultive behavior, compile reports of threats, observe depressed affect, and record accounts of family violence and parental suicidal behavior. An assessment of ego defensive functioning would occur in time only subsequent to the reports of these variables, along with the report of the manifest suicidal behavior. It appears, then, that the utility of a consideration of defenses is as information to consider in estimating a child's capacity for self-protection under stress. Thus, including an assessment of ego defenses in an assessment of a suicidal or potentially suicidal child may assist the clinician in devising an intervention strategy.

For example, a child manifesting suicidal ideation along with a relatively mild depressive reaction to parents' separation or divorce, and who has good reality testing, operative repression, and discharges drives through sublimation and fantasy may require a relatively simple intervention. A seriously depressed child who threatens or attempts suicide, threatens or attacks others, ruminates about death, observes parental violence or suicidal behavior or receives parental abuse may require an intensive, comprehensive intervention. 
The results of Pfeffer et al.'s investigations suggest that an organization of defenses depends on the type of suicidal child identified, that is, from the higher functioning suicidal-only child to the disorganized functioning of the psychotic child with distortions in ego development. Similarities among defenses occurred for inpatient and suicidal children in that developmentally the defenses occur relatively early in the separationindividuation process and are thus less adaptive for latency age children. Although classifying the defenses of denial, introjection, and projection as relatively primitive, these defenses, along with repression, constitute many of the ones utilized by normal children as part of the structure of latency. Perhaps what separates suicidal and psychiatric children from normal ones is an over-reliance on more primitive defenses, particularly when experiencing stressful circumstances, which prevents or delays the acquisition of more appropriate and adaptive defenses for their age. Relatively normal children have acquired more advanced defenses, and thus have a greater range of total defenses, including those which facilitate active coping efforts, e.g., intellectualization and sublimation. Considering the family systems of suicidal children, their acquiring more adaptive defenses seems highly improbable and would in effect create children more adequately developed than some of their own parents. 
Introjection, the one defense appearing consistently in profiles of suicidal children, may illustrate these children's incapacity to internalize loving and nurturing aspects of their parents over hostile ones because of the preponderance of hostility and conflict in their interpersonal relationships. As a less mature mechanism than identification, introjection does not afford opportunities for taking in selected, preferred aspects of their parents; hostile aggression thus predominates. It also predominates because of the daily necessity of adapting to the family environment.

Conversely, the relative lack of reliance on more advanced ego defenses restricts the child's emotional functioning and limits the self-protective capacity. Lacking the defense of sublimation, for example, the child cannot rechannel hostile aggression into constructive activities which would dissipate the hostility. Similarly, without reaction formation the child cannot develop attitudes in opposition to those of parents. Without the self-forgiving function of undoing, the child cannot reduce the impact of the experience of guilt.

Reliance on maladaptive ego defenses constitutes a deficit; hostility and rage as the dominant affects illustrate deviant object representations through expression in aggressive actions; hopelessness as the lack of future expectation ("powered" by various motivations) constitutes 
the cognitive expression of depression; suicidal fantasies as the expression of the child's attempt to provide self care and succor also permit suicidal planning in reality. Life stresses--chaotic families--interfere with the child's attempts to internalize nurturing object-representations subsequent to the critical developmental periods.

The child is left deficient. Hostility and rage dominate as reactions to object losses and defense to a proclivity to depression; reliance on primitive ego defenses interferes with the acquisition of age-appropriate ones; the structure of latency is mutable; fantasy fails in its function of self-esteem protection through gratification and drive discharge and transforms into fantasies of annihilation; failure of fantasy signals the failure of defenses, and suicidal action follows. 


\section{CHAPTER $V$}

\section{CONCEPTUALIZATION OF SUICIDAL BEHAVIOR}

This thesis proposes that suicidal behavior in latency age children results from the failure of their protective psychological mechanisms during periods of intense stress. It further proposes that the failure occurs because suicidal children's ego organizations include disturbances which make them susceptible to self-destructive behavior. That is, suicidal behavior is a possible outcome of a process of disturbed development. Further, this thesis assumes that developmental object relations theory can explain the developmental precursors of suicidal behavior.

Object relations theory emphasizes the development of a child's ego organization and its functioning during the first three years of life based on the principle of orthogenesis. During this period of development, ego development may proceed normally, in which case the child at thirty-six months or so has established the basis for normality in subsequent periods of development. Alternatively, modifications of the developing ego organization may occur as deviations or distortions in 
development; these include the predisposition to disturbances in later periods of development.

The application of object relations theory to the phenomenon of suicidal behavior in latency age children includes certain assumptions and limitations. One assumption holds that the theory's concepts comprise developmental reality and elucidate it.

Another is that successful completion of the tasks of the first three years can account for the establishment of a normal structure of latency. This position disregards the years four through five in which other developmental tasks (e.g., identification with the same sex parent; acquisition of the defenses of regression, intellectualization, and repression; socialization) require negotiation. A consequence of this is the neglect of the effects of developmental disturbances during these years and the ramifications of them for the establishment of the structure of latency and the capacity to exercise self-protective mechanisms.

The assumption that suicidal behavior in latency age children originates exclusively from disturbances during the first three years of life hence seems unwarranted. Developmental tasks, loss, and excessive stress occur throughout development as illustrated by Pfeffer's (1982a) report of suicidal behavior in a child considered neurotic. 
The approach also ignores the effects of inordinate stress encountered by a normal child with an established structure of latency. Studies of suicidal behavior in normal children (Pfeffer et al., 1984, 1985, 1986, 1988) identify a percentage with suicidal ideation and death preoccupations. To infer from these findings that these Ehildren's ego organizations are necessarily disturbed would be fallacious. Disturbances could be suspected and investigated, but not concluded.

Object relations theory may explain the manifestation of suicidal behavior in some latency age children, those with disturbances in ego organization occurring in the first three years of life. It seems unable to account for the phenomenon in all suicidal children and thus lacks the rigor of a unified theory of suicidal behavior in this population. Three cautions accompany the explication which follows. The first is that it applies only to children considered to have experienced disturbances in ego organization during the first three years of life. The second is that evidence derives from studies whose research instruments are in the process of validation. The third is that it is tentative and speculative.

The model of suicidal behavior in latency age children (Figure 2) depicts the developmental sequence of children who may engage in suicidal behavior. For these children, experiences of $105 s$ and/or extreme environmental stress-- 
chaotic, violence prone families, suicidal parents--disturb their developing ego organizations (Bowlby, 1980, Nagera, 1981, Toolan, 1981, Wol fenstein, 1969).

SeparationIndividuation Phases

"Normal"

Autism: birth2 months

"Normal " Symbiosis: 2-6 months

Differentiation: 6-10 months

Practicing: 10-16 months

Rapprochement: 1.6-25 months
Ob ject

Relations

Ego

Functions

Sleeplike state;

alertness and reception of input.

Unity with mother.
Effects of Disturbances
Apparatuses fail to quicken.
Memory traces Premature of "good" and differentbad" experiences. iation Smiling response. of

Capacity for aggression precl udes brief delay. symbiotic union.

Denial

Introjection

Projection

Splitting

Image of mother.

Initial

awareness of

separation.
Curiosity, interest in persons.

\section{Acute stranger anxiety. Sense of di sorgan- ization.}

Specific bond with mother for stability. Elation.

Bal ance self and object i mages. Ambivalence toward objects.
Di f ferentiating cognitive

Wi thout mother, "mini"-

Introjection. Range of emotions.
Failure of maternal response: depression, low sel festeem.

Fiqure 2. Model of suicidal behavior. 
Ident i fication.

Projective

identi ication.

Dbject

Constancy:

24-36+ months
Comfort from

internal object

represent at i on.

Unite good and bad aspects of mother in one

person.
Splitting

of sel $f-$

and objectexperi ence

(al 1-good/

(al 1-bad).

Dependence on object

for sense

of well-

being.

Anxiety and depression re loss of

love.
36 months to six years: from dyadic to triadic object relations.
Regression.

Intel lectualization. Repression.

Normal Development-------Disturbed Devel opment

Stable internal objects Unstable internal objects

6 years

Structure of Latency

Adequate sel f-esteen.

Low sel f-esteen.

Adequate sel f-regulation.

Fluctuating selfregulation.

to Self-confort.

Dependence on others.

Reliable defenses.

Qverreliance on primitive defenses.

Fiqure 2. Model continued. 
Range of emotions.
Predisposed to depression, hostility, anger.

12 years Stressors

\begin{abstract}
(parental support)
Mastery; structure of latency secure.
\end{abstract}

Closs, parental rejection, hostility, abuse, suicidal ideation or behavior)

Failure of structure of latency. Unable to deal with stress through fantasy, for self-comforting fantasies transform into suicidal fantasies which lead to suicidal ideation and planning. Failure of splitting defense permits suicidal behavior to occur.

Figure 2. Model continued.

In the phase of normal symbiosis, 1055 means the loss of union which can occur through lack of maternal response (Hamilton, 1988) or through premature differentiation of separation served by aggression (Blanck \& Blanck, 1979). "Bad" experiences then predominate over "good" ones; a predisposition to aggression and depression results.

Disturbances in the differentiation and practicing phases disrupt the creation of a supportive bond with the mother which interferes with the infant's separation. 
Excessive anxiety and a depressive predisposition result (Mahler, 1986).

Disturbances in the rapprochement phase interfere with the integration of good and bad self- and object-images into a stable sense of a self. Effects include a predisposition to low self-esteem and depressive affect (Blanck \& Blanck, 1974) and difficulty limiting aggression (Fraiberg, 1987). Object constancy consolidates the rapprochement tasks. Disturbances include difficulty comforting oneself (Pine, 1985), perceiving oneself and others as all-good or all-bad (i.e., splitting), difficulty limiting anger, and depression from feeling a loss of love (Hamilton, 1988, Pine, 1985).

These children have internalized primarily negative, hostile object representations and, consequently, developed primarily negative sel f- and object-images (Blanck \& Blanck, 1979, 1986, Hamilton, 1988, Horowitz, 1988). They rely excessively upon primitive psychological mechanisms for self-protection, for the provision of feelings of safety, and for the regulation of self-esteem and self-limiting behavior (Chessick, 1985, Hamilton, 1988, Sarnoff, 1987). The effects include a proclivity to depression through the inability to nurture the self adequately because the selfimage is underdeveloped, sel f-concept is variable, and sel festeen is low (Blanck \& Blanck, 1974, 1986).

In latency-age children the structure of latency provides a period of more or less stable functioning, at 
least so long as the child's psychological mechanisms and environmental support foster the maintenance of the structure of latency (Sarnoff, 1987). Where separationindividuation disturbances occurred, though, the latency organization is impaired to varying degrees.

One impairment is the instability of defense mechanisms relied upon by the child to protect the self from external threats (i.e., environmental stressors) and to limit the expression of hostility. This means that the more developed mechanisms such as repression, sublimation, intellectualization, doing and undoing, and reaction formation are less consistently available for selfprotection than are the more primitive mechanisms of denial in fantasy, introjection, projection, and splitting. Thus, once adaptive mechanisms of the separation-individuation process no longer function adaptively, but maladaptively (Pfeffer et al., 1979, 1980, 1983, 1984, 1986, 1988).

Another impairment consists of the ego organization's inability to sustain nurturing, self-comforting self- and object-representations to protect and sustain the sense of self and self-esteem. That is, during the phases of the separation-individuation process, experiences of loss upset the differentiating and integrating process of the organizing ego, with a consequent modification of organization. This may have occurred through a frustrating relationship with caretakers, or with the loss of the 
nurturing parent in reality. The result is a deficit in the child's ability to meet the task of taking in primarily positive object representations. The child internalizes primarily hostile and negative object-images through projective identification in an attempt to modify disappointing situations in reality. The effect is a deleterious one because of the attendant predominance of hostility and anger over love and nurture. The succeeding disturbances in ego organization predispose the child to suicidal behavior, particularly if the child lives in a chaotic family environment, one with parents who are violent, abusive, and/or suicidal.

The child lacks the ability to effect change in the environment constructively, and may express frustration and rage toward others. Threatening and assaulting others (Cohen-Sandler et al., 1982, Garfinkel et al., 1982, Pfeffer et al. 1983, 1986, 1988) may constitute the behavioral expression of their frustration and $r a g e$ in a sequence of projection and actualization (Sarnoff, 1987).

A severe depressive reaction may constitute another form of the expression of frustration and rage, perhaps the suicidal only group of children identified by Pfeffer et al. (1983).

The structure of latency loses its protectiveness because of reality demands (overwhelming stress) and the child's ego organization's inability to use fantasy to 
obliterate external stresses and maintain itself. Because of the inability to deal constructively with reality demands, the child continues to rely on fantasy as defense. Defense through fantasy may protect the child, but may actually increases the child's susceptibility by transmuting into suicidal fantasies (Friedman \& Corn, 1985, Pfeffer, 1982a, 1985, 1986). Suicidal fantasies may provide a measure of surcease, but have no effect on reality, and transform into death preoccupations and suicidal ideation which presage and allow for as well as constitute suicidal planning.

Coinciding with suicidal fantasies is the child's defensive belief that death is reversible, a belief contrary to the child's comprehension of impersonal death Corbach et al., 1981, 1983, 1984).

Fantasy loses its protective function and transforms into fantasies of escape from an intolerable situation, from pain, or reunion with an all-loving caretaker through death-the motivations for suicide. Fantasies for protection become fantasies of self-destruction which, in turn, become plans for suicidal acts.

The final defense, splitting (Horowitz, 1988, Pine, 1985), allows the child to "totally split off good and bad sensations" (Pfeffer, 1982a. P. 132). The failure of the mechanism to provide relief removes the final defense against self-destruction, and suicidal behavior ensues. 
102

Acting on a suicidal plan, the observable suicidal behavior occurs as a desperate, final step to alleviate suffering. It provides the means whereby the child's ego separates its self-images into all-bad, all-good ones, and becomes a way to preserve the all-good ones while abolishing from consciousness the all-bad ones. The protective controls no longer operate because they have failed to protect sufficiently to prevent a suicidal crisis. Suicidal behavi or follows. 


\section{REFERENCES}

Aber, J. L., \& Allen, J. P. (1987). Effects of maltreatment on young children's socioemotional development: An attachment theory perspective. Developmental Psychology, 23, 406-414.

Adams, P. L., \& Fras, I. (1988). Beqinning Child psychiatry. New York: Brunner/Mazel.

Allen, B. P. (1987). Youth suicide. Adolescence, 22, 271290.

Asarnow, J. R., Carlson, G. A., \& Guthrie, D. (1987). Coping strategies, self-perceptions, hopelessness, and perceived family environments in depressed and suicidal children. Journal of Consulting and Clinical Psychology, 55, 361-366.

Ausubel, D. P. (1952). Eno development and the personality disorders: A developmental approach to Rsychopathologx. New York: Grune and Stratton.

Blanck, G., \& Blanck, R. (1974). Eqo psychology: Theory and practice. New York: Columbia University Press.

Blanck, G., \& Blanck, R. (1979). Eqo psychology II:

Psychoanalytic developmental psychology. New York: Columbia University Press.

Blanck, G., \& Blanck, R. (1986). Bexond eqo psychol ogy: Developmental object relations theory. New York: Columbia University Press.

Bowlby, J. (1980). Loss: Sadness and depression: Attachoent and loss: Vol. III. New Yorks Basic Books.

Brody, S. (1982). Psychoanalytic theories of infant development and its disturbancess A critical evaluation. Psychoanalytic Quarterly, 51, 526-597.

Carlson, G. A., Asarnow, J. R., \& Orbach, I. (1987). Developmental aspects of suicidal behavior in children: I. Journal of the American Academy of Child and Adolescent Psychiatry, 26, 186-192. 
Carlson, G. A., \& Cantwell, D. P. (1982). Suicidal behavior and depression in children and adolescents. Journal of the American Academy of Child Psychiatry. 21. 361-368.

Chessick, R. D. (1985). Psychologx of the self and the treatment of narcissism. Northvale, NJ: Aronson.

Cicchetti, D., \& Schneider-Rosen, K. (1984). Toward a transactional model of childhood depression. In D. Cicchetti \& K. Schneider-Rosen (Eds.), New directions for child development: No. 26. Childhood depression (pp. 5-27). San Francisco: Jossey-Bass.

Cohen-Sandler, R., Berman, A. L., \& King, R. A. (1982). Life stress and symptomatology: Determinants of sucidal behavior in children. Journal of the American Academy of Child Psychiatry, 21, 178-186.

Cowan, P. A. (1988). Developmental psychopathology: A nine-cell map of the territory. In E. D. Nannis \& $P$. A. Cowan (Eds.), New directions for child development: No. 39. Developmental psychopathology and its treatment (pp . 5-29). San Franci scos Jossey-Bass.

Fraiberg, L. (Ed.). (1987). Selected writings of Selma Fraiberg. Columbus: Ohio State University Press.

Freud, A. (1966). The ego and the mechanisms of defense (Rev. ed.). New York: International Universities Press.

Friedman, R. C., Corn, R., Hurt,S. W., Fibel, B., Schulick, J., S Swirsky, S. (1984). Family history of illness in the seriously suicidal adolescent: A life-cycle approach. American Journal of Orthopsychiatry, 54, 390-397.

Friedman, R. C., \& Corn, R. (1985). Follow-up five years after attempted suicide at age 7. American Journal of Psychotherapy, 39, 108-113.

Garber, J. The developmental progression of depression in female children. In D. Cicchetti \& K. Schneider-Rosen (Eds.), New directions for child development. No. 26. Childhood depression (pp. 29-58). San Francisco: Jossey-Bass.

Garfinkel, B. D., Froese, A., \& Hood, J. (1982). Suicide attempts in children and adolescents. American Journal of Psychiatry, 139, 1257-1261. 
Gould, R. E. (1965). Suicide problems in children and adolescents. American Journal of Psychotherapy, 19, 228-246.

Hamilton, N. G. (1988). Self and otmerse Doject relations theory in practice. Northvale, NJ: Aronson.

Hawton, K. (1982). Attempted suicide in children and adolescents. Journal of Child Psychology a $n d$ Psychiatry and Allied Disciplines, 23, 497-503.

Horner, A. J. (1984). Dbject relations and the developing eqo in therapy (rev. ed.). Northvale, NJ: Aronson.

Horner, T. M. (1988). Rapprochement in the psychic development of the toddler: A transactional perspective. American Journal of Orthopsychiatry, 58 , 4-15.

Horowitz, M. J. (1988). Introduction to psychodynamics: A new synthesis. New York: Basic Books.

Hutchinson, M. P., \& Draguns, J. G. (1987). Chronic, early exposure to suicidal ideation in a parental figure: $A$ pattern of presuicidal characteristics. Suicide and Life-Threatening Behavior, 17, 288-298.

Joffe, R. T., \& Offord, D. R. (1983). Suicidal behaviour in childhood. Canadian Journal of Psychiatry, 2B, 5763.

Kazdin, A. E., French, N. H., Unis, A. S., Esveldt-Dawson, \& Sherick, R. B. (1983). Hopelessness, depression, and suicidal intent among psychiatrically disturbed inpatient children. Journal of Consulting and Clinical Psychologx, 51, 504-510.

Kennedy, H., \& Moran, G. S. (1984). The developmental roots of self-injury and response to pain in a 4-yearold boy. The Psychoanalytic Study of the Child, 39. 190-212.

Kernberg, 0. (1980). Internal world and external reality: object relations theory applied. New York: Aronson.

Kienhorst, C. W. M., Wolters, W. H. G., Diekstra, R. F. W., \& ottie, E. (1987). A study of the frequency of suicidal behaviour in children aged 5 to 14 . Journal of Child Psychology and Psychiatry, 2B, 153-165.

Koocher, G. P. (1973). Childhood, death, and cognitive devel opment. Developmental Psychology, 9, 369-375. 
Kosky, R. (1983). Childhood suicidal behaviour. Journal of thild Psychology and Psychiatry, 24, 457-468.

Kosky, R., Silburn, S., \& Zubrick, S. (1986). Symptomatic depression and suicidal ideation: A comparative study with 628 children. The Journal of Nervous and Mental Di sease, 174, 523-528.

Laughlin, H. P. (1983). The eqo and its defenses (2nd ed.) Northvale, NJ: Jason Aronson.

Mahler, M. S. (1986). On the first three subphases of the separation-individuation process. In P. Buckley (Ed.), Essential papers on object relations (pp. 222232). New York: New York University Press.

McGuire, D. J., \& Ely, M. (1984). Childhood suicide. Child Wel fare, 63, 17-26.

Myers, K. M., Burke, P., \& McCauley, E. (1985). Suicidal behavior by hospitalized preadolescent children on a psychiatric unit. Journal of the American Acadeny of Child Psychiatry, 24, 474-480.

Nagera, H. (1981). The developmental approach to childhood psychopathology. New York: Aronson.

Orbach, I., Feshbach, S., Carlson, G., Ellenberg, L. (1984). Attitudes toward 1 ife and death in suicidal, normal, and chronically ill children: An extended replication. Journal of Consulting and Clinical Psycholony, 52, 1020-1027.

Orbach, I., Feshbach, 5. Carlson, G., Glaubman, H., \& Gross, $Y$. (1983). Attraction and repulsion by 1 ife and death in suicidal and in normal children. Journal of Consulting and Clinical Psychology, 51, 661-670.

Orbach, I., \& Glaubman, H. (1978). Suicidal, aggressive, and normal children's perception of personal and impersonal death. Journal of Clinical Psychology, 34, 850-857.

Orbach, I., \& Gl aubman, H. (1979a). Children's perception of death as a defensive process. Journal of Abnormal Psychology, 88, 671-674.

Orbach, I., \& Glaubman, H. (1979b). The concept of death and suicidal behavior in young children: Three case studies. Journal of the American Academy of Child Psychiatry, 18, 668-678. 
Orbach, I., Gross, Y., \& Gl aubman, H. (1981). Some common characteristics of latency-age suicidal children: A tentative model based on case study analyses. Suicide and Life-Threatening Behavior, 11, 180-190.

Orbach, I., Rosenheim, E., \& Hary, E. (1987). Some aspects of cognitive functioning in suicidal children. Journal of the American Academy of Child and Adolescent Psychiatry, 26, 181-185.

Orvaschel, H., Walsh-Allis, G., \& Ye, W. (1988). Psychopathology in children of parents with recurrent depression. Journal of Abnormal Child Psychology, 16, 17-28.

Paulson, M. J., Stone, D., \& Sposto, R. (1978). Suicide potential and behavior in children ages 4 to 12. Suicide and Life-Threatening Behavior, B, 225-242.

Pfeffer, C. R. (1981a). The distinctive features of children who threaten and attempt suicide. In C. F. Wells \& I. R. Stuart (Eds.), Self-destructive behavior in children and adolescents (PP. 106-120). New York: Van Nostrand Reinhold.

Pfeffer, C. R. (1981b). The family system of suicidal children. American Journal of Psychotherapy, 35, 330341 .

Pfeffer, C. R. (1982a). Clinical observations of suicidal behavior in a neurotic, a borderline, and a psychotic child: Common processes of symptom formation. Child Psychiatry and Human Devel opment, 13, 120-134.

Pfeffer, C. R. (1982b). Interventions for suicidal children and their parents. Suicide and LifeThreatening Behavior, 12, 240-248.

Pfeffer, C. R. (1985). Suicidal fantasies in normal children. The Journal of Nervous and Mental Disease, 173, 78-84.

Pfeffer, C. R. (1986). The suicidal child. New York: Guil ford.

Pfeffer, C. R. (1987). Elements of treatment for suicidal preadolescents. American Journal of Psychotherapy, 41, 172-184. 
Pfeffer, C. R., Conte, H. R., Plutchik, R., \& Jerrett, I. (1979). Suicidal behavior in latency-age children: An empirical study. Journal of the American Academy of Child Psychiatry, 18, 679-692.

Pfeffer, C. R., Conte, H. R., Plutchik, R., \& Jerrett, I. (1980). Suicidal behavior in latency-age children: An outpatient population. Journal of the American Academy of Child Psychiatry, 19, 703-710.

Pfeffer, C. R., Lipkins, R., Plutihik, R., \& Mizruchi, M. (1988). Normal children at risk for suicidal behavior: A two-year follow-up study. Journal of the American Academy of Child and Adolescent Psychiatry, 27. 34-41.

Pfeffer, C. R., Plutchik, R., \& Mizruchi, M. S. (1983). Suicidal and assaultive behavior in children: Classification, measurement, and interrelations. American Journal of Psychiatry, 140, 154-157.

Pfeffer, C. R., Plutihik, R., Mizruchi, M. S., \& Lipkia., M. A. (1986). Suicidal behavior in child psychiatric inpatierits and outpatients and in nonpatients. American Journal of Psychiatry, 143, 733-738.

Pfeffer, C. R., Zuckerman, S., Plutchik, R., \& Mizruchi, M. 5. (1984). Suicidal behavior in normal school children: A comparison with child psychiatric inpatients. Journal of the American Academy of Child Psychiatry, 23, 416-423.

Piaget, J., \& Inhelder, B. (1969). The psychology of the child. New York: Basic Books.

Pine, F. (1985). Developmental theory and clinical process. New Haven: Yale University Press.

Rosenthal, P. A., Rosenthal, S., Doherty, M. B., \& Santora, D. (1986). Suicidal thoughts and behaviors in depressed hospitalized preschoolers. American Journal of Psychotherapy, 40, 201-212.

Santostefano, S., Rieder, C., \& Berk, S. A. (1984). The structure of tantasied movement in suicidal children and adolescents. Suicide and Life-Threatening Behavior, 14, 3-16.

Sarnoff, C. A. (1987). Psychotherapeutic strateqies in the latency years. Northvale, $\mathrm{NJ}$ : Jason Aronson. 
Schechter, M. D. (1957). The recognition and treatment of suicide in children. In E. S. Schneidman \& N. L. Farberow (Eds.), Clues to suicide (Pp. 131-142). New York: McGraw-Hili.

Shaffer, D. (1974). Sulcide in childhood and early adolescence. Journal of Child Psychology and Psychiatry, 15, 275-291.

Shaffer, D., \& Fisher, P. (1981a). The epidemiology of suicide in children and young adolescents. Journal of the American Academy of Child Psychiatry, 20, 545-565.

Shaffer, D., \& Fisher, P. (1981b). Suicide in children and young adolescents. In $C$. F. Wells \& I. R. Stuart (Eds.), Self-destructive behavior in children and adolescents (PP. 75-104). New York: Van Nostrand Reinhold.

Shafii, M., Carrigan, S., Whittinghill, J. R., \& Derrick, A. Psychological autopsy of completed suicide in children and adolescents. American Journal of Psychiatry, 142, 1061-1064.

Shapiro, T., \& Perry, R. (1980). Latency revisited: The age seven, plus or minus one. In 5 . I. Harrison \& J. F. MeDermott (Eds.), New directions in childhood psychopathology: $V$. I: Developmental considerations (pp. 161-177). New York: International Universities Press.

Shaw, C. R., \& Schelkun, R. F. (1965). Suicidal behavior in children. Psychiatry: Journal for the Study of Interpersonal Processes, 28, 157-168.

Sroufe, A. L., \& Rutter, M. (1984). The domain of developmental psychopathology. Child Development, 55, 17-29.

Toolan, J. M. (1962). Suicide and suicidal attempts in children and adolescents. American Journal of Psychiatry, 118, 719-724.

Toolan, J. M. (1981). Depression and suicide in children: An overview. American Journal of Psychotherapy, 35, 311-322.

Velez, C. N., \& Cohen, P. (1988). Suicidal behavior and ideation in a community sample of children: Maternal and youth reports. Journal of the American Academy of Child and Adolescent Psychology, 27, 349-356. 
Wal rond-Skinner, S. (1986). A dictionary of psychotherapy. New York: Routledge \& Kegan Paul.

Wol fenstein, M. (1969). Loss, rage, and repetition. The Psychoanalytic Study of the Child, 24, 432-460. 